\title{
Carbon and Energy Intensity of the USA and Germany. A LMDI Decomposition Approach and Decoupling Analysis.
}

Eleni Koilakou ( $\nabla$ elenikoilakou@gmail.com )

Panteion University

Emmanouil Hatzigeorgiou

Panteion University

Kostas Bithas

Panteion University

\section{Research Article}

Keywords: LMDI decomposition analysis, $\mathrm{CO} 2$ emissions, energy intensity, decoupling effect, scenario analysis, the United States, Germany.

Posted Date: December 13th, 2021

DOI: https://doi.org/10.21203/rs.3.rs-1119478/v1

License: (c) (i) This work is licensed under a Creative Commons Attribution 4.0 International License. Read Full License 
a. Institute of Urban Environment \& Human Resources, Department of Economic \& Regional Development, Panteion University, 29 Aristotelous Street, GR-17671, Kallithea, Athens, Greece

b. Center for Systems Integration \& Sustainability, Michigan State University, Manly Miles Building, 1405 South Harrison Road East Lansing, MI 48823-5243, USA

c. Energy Management Laboratory, Department of Environment, University of the Aegean, University Hill, 81100, Lesvos, Greece

*Corresponding author at: Institute of Urban Environment \& Human Resources, Department of Economic \& Regional Development, Panteion University, 29 Aristotelous Street, GR-17671, Kallithea, Athens, Greece. E-mail addres: elenikoilakou@gmail.com . 


\begin{abstract}
The present study investigates the driving factors of energy and carbon intensity of the great economies of the USA and Germany, being two economies with different structures and dependencies on energy while they are among the world's economic and geopolitical leading players. Both Decoupling and Decomposition Analysis are applied to identify and rank factors defining Carbon and Energy Intensity during the period from 2000 to 2017, with the so-called financial crisis being within this period. The decoupling analysis denotes that these advanced economies should enhance their decoupling efforts, while decomposition analysis confirms the leading role of energy intensity in $\mathrm{CO}_{2}$ emissions, next the income and the energy mix emerge as important factors with population trend to be an additional factor only in the USA. Finally, conclusions and relevant policy suggestions are presented.
\end{abstract}

Keywords: LMDI decomposition analysis, $\mathrm{CO}_{2}$ emissions, energy intensity, decoupling effect, scenario analysis, the United States, Germany.

\title{
1. Introduction
}

Trends of $\mathrm{CO}_{2}$ emissions as well as of carbon intensity of the economy are of prominent importance within the frameworks of contemporary economies and energy policies. $\mathrm{CO}_{2}$ emissions and carbon intensity are the outcome of several factors including the efficient use of energy, energy mix (fossil fuels versus renewables), and growth trends and structure, income level and population. The evolution and ranking of the driving forces of $\mathrm{CO}_{2}$ emissions is an issue of scientific and policy importance. The present study attempts an investigation over the Carbon and Energy Intensity of the great economies of the USA and Germany attempting to identify the key driving forces.

The international literature proves that the driving forces of economic and demographic growth, geopolitical changes, international trade and western society's lifestyle are inducing high energy consumption and coupling between growth and $\mathrm{CO}_{2}$ emissions (Hatzigeorgiou et al., 2008). Various methods have been developed to evaluate and rank the factors driving energy consumption and $\mathrm{CO}_{2}$ emissions, including the Index Decomposition Analysis (IDA) methodology (Ang, 1999; Wang et al., 2018) and decoupling analysis (Tapio, 2005). The present article investigates the driving forces behind the trends of the energy-related $\mathrm{CO}_{2}$ emissions in Germany and in the United States of America (USA) from 2000 to 2017. The paper attempts a decomposition analysis by means of the Logarithmic Mean Divisia Index (LMDI) method while combining it with a set of decoupling indexes. The leading role of these two advanced economies in the continents of America and Europe, their different structures and evolutionary trajectories as well as different mixtures of energy and climate policies induced the comparison between these two giant economies with tremendous influence at the global scale.

For the USA, a number of studies investigate the driving factors of $\mathrm{CO}_{2}$ emissions. Vinuya et al. (2010) analyzed the trends of $\mathrm{CO}_{2}$ emissions for the USA economy employing the LMDI technique. The authors concluded that the decline of energy intensity was the causal effect for the reduction of $\mathrm{CO}_{2}$ emissions. Baldwin and Wing (2013) studied the spatiotemporal evolution of $\mathrm{CO}_{2}$ emissions for the USA economy employing a permutation of Kaya identity, over the period 1963-2008. The results denoted that energy efficiency improvement and compositional shifts were the causal factors for the decrease of $\mathrm{CO}_{2}$ emissions. 
Shahiduzzaman and Layton (2017) analyzed the feasibility of the Greenhouse Gases (GHGs) target for 2025, employing the additive LMDI technique. Their analysis indicated that Gross Domestic Product (GDP) and Population effects were the main contributors on the increase of total $\mathrm{CO}_{2}$ emissions for the years 2000-2014, while Energy Intensity had the biggest negative contribution.

Wang et al. (2018) compared $\mathrm{CO}_{2}$ emissions in the China and the USA by an LMDI approach combined with a decoupling analysis of $\mathrm{CO}_{2}$ emissions from economic growth. The study showed that the main reasons for the decrease of $\mathrm{CO}_{2}$ emissions in China and the USA are income and population effects followed by the energy intensity and the energy mix effects. Jiang et al. (2019), based on Cobb-Douglas (C-D) production function and LMDI technique, examine the evolution of $\mathrm{CO}_{2}$ emissions in the USA. The study quantified the impact of the technological status on $\mathrm{CO}_{2}$ emissions for the USA. Song et al. (2019) established a twodimensional model for the relationship between economic development and $\mathrm{CO}_{2}$ emissions in China and the USA. The methodology was based on Tapio (2005) decoupling index and Environmental Kuznets Curve (EKC) for 1965-2016. The results depicted that strong decoupling has not achieved. Wang et al. (2020) implied an aggregate and sectoral decomposition analysis of $\mathrm{CO}_{2}$ emissions for the USA over 1997-2016. The study resulted that the main influencing factor is the scale effect (income and population), while the technology effect (energy intensity and emission coefficient) is the key driving force in mitigating emissions.

119 Regarding the case of Germany, the studies on the identification of the driving forces of $\mathrm{CO}_{2}$ emissions are numerous. Bhattacharyya and Matsumura (2010) analyzed the decline of greenhouse gas emissions in European Union (EU) over the period 1990-2007, employing the LMDI decomposition technique. Their paper revealed that the reduction of the energy intensity in the EU-15 is attributable to significant improvements by large emitters such as Germany and the UK. Gonzalez et al. (2014) suggested environmental and energy strategies in order to control $\mathrm{CO}_{2}$ emissions using LMDI technique, in the EU-27. The results signified the negative impact of the energy intensity and fuel mix effects and the positive impact of the population, income and emission factor for the change of the $\mathrm{CO}_{2}$ emissions.

Ward et al. (2016) established a simple model based on IPAT equation questioning the possibility of Decoupling of GDP growth from environmental impacts, for selected countries. The model showed that GDP growth cannot be decoupled from energy use. Cohen et al. (2018) evince the existence of decoupling between GHG emissions and economic growth using a simple trend/cycle decomposition for Germany (1990-2014). Sadorsky (2020) studied the driving factors of energy-related $\mathrm{CO}_{2}$ emissions in the time of financial crisis, applying the LMDI technique. The decrease in energy intensity was the key driver behind declining $\mathrm{CO}_{2}$ emissions, while an increase in GDP was the biggest force enlarging $\mathrm{CO}_{2}$ emissions. Haein et al. (2020) used the LMDI technique for decomposing $\mathrm{CO}_{2}$ emissions from electricity generation, employing a comparative analysis of 36 OECD countries. The study proved that the improvement in electricity intensity (ELI), calculated as electricity generation per GDP (EL/GDP), and the decrease in the share of thermal generation were the main effects for the reduction of $\mathrm{CO}_{2}$ emissions.

141 Other scholars, in recent papers, focused on the evolution of GHGs for China as a large 142 economy, by means of decomposition or/and decoupling analysis (Fatima et al., 2019; Yang 143 et al., 2020; Zhang et al., 2020; Hu et al., 2021). 
144 Contributing to the above-mentioned literature with new evidence, the objective of this article

145 is to evaluate and analyze the energy and $\mathrm{CO}_{2}$ intensity of the USA and Germany, an issue 146 with high policy relevance. Remarkably, the GDP of German economy accounted for $24.07 \%$ 147 of the EU (The World Bank Group, 2020). In 2018, the global share of $\mathrm{CO}_{2}$ emissions for 148 USA is $14.7 \%$ (IEA, 2020a) and the USA GDP accounted for $21.54 \%$ of the global GDP 149 (The World Bank Group, 2020). Although a number of past studies have concentrated on $150 \mathrm{CO}_{2}$ emissions and economic output for various countries, a comparative analysis of driving 151 factors for energy-related $\mathrm{CO}_{2}$ emissions between the two major economies, USA and 152 Germany, is not widely presented in the energy literature. The proposed analysis could 153 provide valuable insight in existent and future energy and environmental policies of the two 154 economies.

155 First, we conduct a descriptive and structural comparative analysis between the two 156 economies, delineating their energy status and we set a baseline scenario, examining whether 157 the recent emission targets of the two economies are attainable. Next, we are employing a set of decoupling indexes to explore the linkage between the energy-related $\mathrm{CO}_{2}$ emissions and economic growth. Finally, we are applying robust LMDI techniques in order to rank and quantify the driving forces leading $\mathrm{CO}_{2}$ emissions. The period under investigation is from 2000 to 2017.

162 Regarding the environmental policies, Germany follows the Climate Action Law (the 163 German first national climate law) which has been included in German government coalition's 2030 climate package. In accordance with the above the targets are a reduction in greenhouse gas emissions up to $55 \%$ by 2030 and to become greenhouse gas neutral by 2050 . Those objectives have been inspired for the respective EU policies (BMWI, 2019; European Commission, 2020a). On the other hand, the target of the USA economy is to reduce $\mathrm{CO}_{2}$ emissions by $26-28 \%$ in 2025 compared to $2005^{1}$, as submitted to the UNFCCC (United Nations Framework Convention on Climate Change).

170 The main energy and climate policy targets of the two countries for the study period 19901712017 are summarized in the Table 1:

${ }^{1}$ https://www4.unfccc.int/sites/submissions/inde/Submission\%20Pages/submissions.aspx 
1990: Federal 1999: Germany government committed to reduce carbon dioxide emissions to 25\% below 1990 levels by 2005. (First Initiative, 1990) Also, Germany agreed that by 2020, GHG

emissions would drop 40\% from 1990 levels (Bailey and Rupp, 2004).
1990: Under the UNFCCC, the USA committed to the voluntary goal of holding greenhouse gas emissions at the end of the 1990s decade to their 1990 levels (Blodgett et al., 2002). signed the Kyoto Protocol and has committed to reduce its emissions to $21 \%$ below 1990 levels between 2008 and 2012 (Telli at al., 2020).

1997: In the
1997 Kyoto
Protocol to the
UNFCCC, the
USA
participated in
negotiations
that ended with
agreement on
further
reductions that
could become
legally binding
(Blodgett et al.,
2002).

1997: In th UNFCCC, the negotiations at ended with furthe ductions that legally binding 2002)

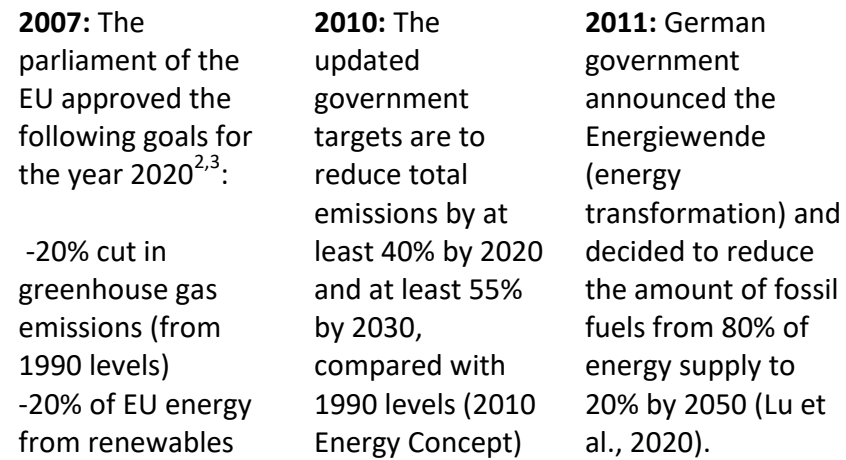

2007: The $-20 \%$ improvement in energy efficiency.
2016: Germany follows the European Council agreement submitted to UNFCCC for a reduction in GHG within the EU of at least $40 \%$ by 2030 , compared with 1990 (BMUB, 2016).

\author{
2002: The Administration \\ rejected the Kyoto Protocol. \\ The goal is to reduce GHG \\ intensity by $18 \%$ over the next \\ 10 years through voluntary \\ activities, which means that the \\ 183 metric tons of carbon \\ emissions (MMTCE) per million \\ dollars of GDP that the United \\ States is emitting in 2002 would \\ fall to 151 MMTCE per million \\ dollars of GDP in 2012 \\ (Blodgett et al., 2002).
}

2014: USA's target as submitted to the UNFCCC, aims at reducing $\mathrm{CO}_{2}$ emissions by $26-28 \%$ in 2025 compared to $2005^{4}$.
2017: Under the Paris Agreement, the USA. promised to achieve a reduction of about $25 \%$ by 2025 compared with 2005 levels ${ }^{5,6}$ (2016). The next year, it announced the USA. with drawal from the Paris Agreement ${ }^{7}$. In 2021, the USA rejoined the Paris Agreement ${ }^{8}$.

Table 1. Emission Goals for the USA and Germany (1990-2017).

As we can see in Table 1 the policy regulations for Germany usually set a strict target in order to achieve a significant reduction of the $\mathrm{CO}_{2}$ emissions in the future. On the other hand, the USA energy and environmental policy set a more achievable target for the reduction of $\mathrm{CO}_{2}$ emissions, although they have several commitment gaps in this attempt because of their Administration changes over time.

In addition, these two economies are among the largest carbon-emitting countries in the world (15,7\% of global $\mathrm{CO}_{2}$ emissions in 2020) as stated in recent COP26, the aim of keeping

\footnotetext{
${ }^{2}$ https://ec.europa.eu/clima/policies/strategies/2020_en

${ }^{3} \mathrm{https}$ ://www.eea.europa.eu/themes/climate/trends-and-projections-in-europe/trends-and-projections-in-europe-2017/overallprogress-towards-the-european

${ }^{4}$ https://www4.unfecc.int/sites/submissions/inde/Submission\%20Pages/submissions.aspx

5 https://unfecc.int/node/61231

${ }^{6} \mathrm{https}: / /$ unfccc.int/process-and-meetings/the-paris-agreement/the-paris-agreement

${ }^{7} \mathrm{https}$ ://www.state.gov/on-the-u-s-withdrawal-from-the-paris-agreement/

8 https://www.state.gov/the-united-states-officially-rejoins-the-paris-agreement/
} 
alive the goals of Paris Agreement. Consequently, their environmental and energy status is of great interest to be studied in depth.

The remainder of the paper is organized as follows: Section $2 \& 3$ present the methodology used and the data analysis, respectively. Results and discussion are described in Section 4. Section 5 summarizes the conclusions.

\section{Methods}

We conduct a Decoupling Analysis between energy-related $\mathrm{CO}_{2}$ emissions $(C)$ and economic growth for the USA and Germany. Decoupling $\mathrm{CO}_{2}$ emissions with economic development is essential for environmental management.

We estimate the Decoupling Index $(D I)$ for the standard $C / G D P$ ratio:

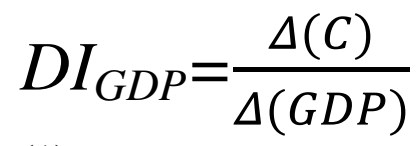

$$
=\frac{\left(C_{t}-C_{t-1}\right) / C_{t-1}}{\left(G D P_{t}-G D P_{t-1}\right) / G D P_{t-1}}
$$

and we estimate the DI for the C/Income ratio:

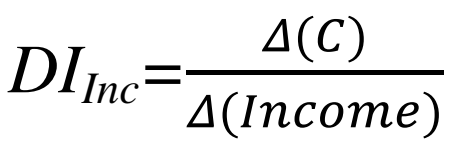

$$
=\frac{\left(C_{t}-C_{t-1}\right) / C_{t-1}}{\left(\text { Income }_{t}-\text { Income }_{t-1}\right) / \text { Income }_{t-1}}
$$

We also set the $E I_{G D P}=E / G D P$ and $E I_{I n c}=E /$ Income energy intensity ratios. The $C I_{\text {Inc }}=C /$ Income carbon intensity ratio is proposed as an indicator that approximates better than the $C I_{G D P}=C / G D P$ ratio the real-world properties of production. In accordance with the existing literature, the indexes $\mathrm{DI}_{\mathrm{Inc}}$ and $\mathrm{CI}_{\mathrm{Inc}}$ denote weaker decoupling trends than the $\mathrm{DI}_{\mathrm{GDP}}$ and $\mathrm{CI}_{\mathrm{GDP}}$ respectively (Bithas and Kalimeris, 2013; Bithas and Kalimeris, 2018). The categorization of the decoupling states is based on the study of Tapio (2005).

Time series Decomposition Analysis is employed to assess the evolution of the decomposition factors during the 2000-2017, in the USA and Germany. LMDI technique is applied to determine and rank the causal effects leading the trends of $\mathrm{CO}_{2}$ emissions in a comparative basis. This technique has emerged as the most preferred IDA technique among researchers and analysts for ease of formulation and simplicity sake. Moreover, LMDI technique is extensively utilized because results in incomplete decomposition and gives zero residual term (Hatzigeorgiou at al., 2008; Yasmeen et al., 2020).

The following variables are defined for each year:

$\begin{array}{ll}i & \text { fuel type (coal, oil, natural gas, renewable resources) } \\ E_{i} & \text { energy consumption of fuel type } i \text { (Mtoe) } \\ E & \text { total energy consumption (Mtoe) } \\ C & \text { total } \mathrm{CO}_{2} \text { emissions }\left(\mathrm{MtCO}_{2}\right) \\ C_{i} & \mathrm{CO}_{2} \text { emissions from fuel type } i\left(\mathrm{MtCO}_{2}\right)\end{array}$


$Y$

$P$

GDP (million 2010US\$ for Germany/ million 2012US\$ for the USA) Population (in million people)

232

260

261

262

263

264 265

266 267

268

The energy-related $\mathrm{CO}_{2}$ emissions $(\mathrm{C})$ are given by the Equation:

$$
C=\sum_{i=0}^{4} I S_{i} P \operatorname{Inc} F_{i}=\sum_{i=0}^{4}\left(\frac{E}{G D P}\right)\left(\frac{E_{i}}{E}\right) P\left(\frac{G D P}{P}\right)\left(\frac{C_{i}}{E_{i}}\right)
$$

Where

- Energy Intensity as $I=\frac{E}{G D P}$

○ Energy Structure as $S_{i}=\frac{E_{i}}{E}$

$\bigcirc \quad$ Income as $\operatorname{Inc}=\frac{G D P}{P}$

$\circ \quad$ Emission factor as $F_{i}=\frac{C_{i}}{E_{i}}$

○ Population as $\mathrm{P}$

In additive LMDI technique, the difference in $\mathrm{CO}_{2}$ emission levels between two years can be expressed in $\mathrm{MtCO}_{2}$ as follows:

$$
\Delta C_{\text {tot }}=\Delta C_{\mathrm{p}}+\Delta C_{\mathrm{inc}}+\Delta C_{\mathrm{int}}+\Delta C_{\mathrm{f}}+\Delta C_{\mathrm{s}}=C_{\mathrm{T}}-C_{0}
$$

where $\Delta C_{\text {tot }}$ is the change of total $\mathrm{CO}_{2}$ emissions.

The relevant formulae for the decomposition factors are as follows:

$$
\Delta C_{\mathrm{p}}=\sum_{i=1}^{4} \frac{\left(C_{i, T}-C_{i, 0}\right)}{\ln \left(C_{i, T} / C_{i, 0}\right)} \ln \left(\frac{P_{T}}{P_{0}}\right)
$$

$$
\Delta C_{\mathrm{inc}}=\sum_{i=1}^{4} \frac{\left(C_{i, T}-C_{i, 0}\right)}{\ln \left(C_{i, T} / C_{i, 0}\right)} \ln \left(\frac{I n c_{T}}{\operatorname{Inc} c_{0}}\right)
$$

$$
\Delta C_{\mathrm{int}}=\sum_{i=1}^{4} \frac{\left(C_{i, T}-C_{i, 0}\right)}{\ln \left(C_{i, T} / C_{i, 0}\right)} \ln \left(\frac{I_{T}}{I_{0}}\right)
$$

$$
\Delta C_{\mathrm{f}}=\sum_{i=1}^{4} \frac{\left(C_{i, T}-C_{i, 0}\right)}{\ln \left(C_{i, T} / C_{i, 0}\right)} \ln \left(\frac{F_{i, T}}{F_{i, 0}}\right)
$$

$$
\Delta C_{\mathrm{s}}=\sum_{i=1}^{4} \frac{\left(C_{i, T}-C_{i, 0}\right)}{\ln \left(C_{i, T} / C_{i, 0}\right)} \ln \left(\frac{S_{i, T}}{S_{i, 0}}\right)
$$


where $\Delta C_{\mathrm{p}}$ is the change of population, $\Delta C_{\text {inc }}$ the change of income, $\Delta C_{\text {int }}$ the change of the energy intensity, $\Delta C_{\mathrm{f}}$ the change of the emission factor and $\Delta C_{\mathrm{s}}$ the change of the energy structure.

In multiplicative LMDI technique, the change scheme is:

$D_{\text {tot }}=D_{\mathrm{p}} D_{\text {inc }} D_{\text {int }} D_{\mathrm{f}} D_{\mathrm{s}}=C_{\mathrm{T}} / C_{0}$

where $D_{\text {tot }}$ is the change of total $\mathrm{CO}_{2}$.

The relevant formulae for the decomposition factors are as follows:

$D_{\mathrm{p}}=\exp \left(\sum_{i=1}^{4} \frac{\left(C_{i, T}-C_{i, 0}\right) /\left(\ln C_{i, T}-\ln C_{i, 0}\right)}{\left(C_{T}-C_{0}\right) /\left(\ln C_{T}-\ln C_{0}\right)} \ln \left(\frac{P_{T}}{P_{0}}\right)\right)$

287

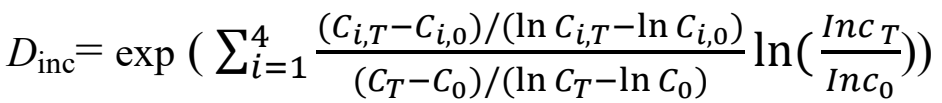

$D_{\text {int }}=\exp \left(\sum_{i=1}^{4} \frac{\left(C_{i, T}-C_{i, 0}\right) /\left(\ln C_{i, T}-\ln C_{i, 0}\right)}{\left(C_{T}-C_{0}\right) /\left(\ln C_{T}-\ln C_{0}\right)} \ln \left(\frac{I_{T}}{I_{0}}\right)\right)$

$D_{\mathrm{f}}=\exp \left(\sum_{i=1}^{4} \frac{\left(C_{i, T}-C_{i, 0}\right) /\left(\ln C_{i, T}-\ln C_{i, 0}\right)}{\left(C_{T}-C_{0}\right) /\left(\ln C_{T}-\ln C_{0}\right)} \ln \left(\frac{F_{i, T}}{F_{i, 0}}\right)\right)$

291

292

$D_{\mathrm{S}}=\exp \left(\sum_{i=1}^{4} \frac{\left(C_{i, T}-C_{i, 0}\right) /\left(\ln C_{i, T}-\ln C_{i, 0}\right)}{\left(C_{T}-C_{0}\right) /\left(\ln C_{T}-\ln C_{0}\right)} \ln \left(\frac{S_{i, T}}{S_{i, 0}}\right)\right)$

where $D_{\mathrm{p}}$ is the change of population, $D_{\text {inc }}$ the change of income, $D_{\text {int }}$ the change of the energy intensity, $D_{\mathrm{f}}$ the change of the emission factor and $D_{\mathrm{s}}$ the change of the energy structure.

\section{Data and Analysis}

\subsection{Data comparison for the economies of the USA and Germany}

The trends of the key variables of our study are presented in Figures S1-S6 in the supplementary information file. Figures S1 and S2 indicates the trends of the main fuels in energy consumption: oil, natural gas, renewable resources and coal, with data drown from the International Energy Agency (IEA, 2020a). The share of nuclear energy is negligible for the two economies. Electricity is not considered to be a separate fuel; it is taken into account via the original fossil fuels that are utilized to produce electricity (Hatzigeorgiou et al., 2010). Renewable resources for Germany present a remarkable increase by $220 \%$ through the last 17 years, while in the USA the increase of renewables is approximately $52 \%$. The share of oil, the fuel with the largest energy consumption, declines for both Germany $(-17.5 \%)$ and the USA $(-6.7 \%)$. 
To estimate $\mathrm{CO}_{2}$ emissions from primary fuel consumption we adopted the OECD emission coefficients (IPCC, 2006), depicted in Table S1 in the supplementary information file. Energy-related $\mathrm{CO}_{2}$ emissions follow significant fluctuations (Fig.S3), with remarkable decrease for the 2006-2007 time period in Germany and 2007-2009 in the USA Remarkably, these time periods coincide with the onset of the financial crisis.

The World Bank Open Data are adopted for the aggregate values of Germany's GDP (The World Bank Group, 2020), while the GDP of the USA is based on data from Bureau of Economic Analysis (BEA, 2020). An upward trend of GDP for both countries is shown in Fig.S4, with the exception of the 2007-2009 time period; GDP for Germany declined by 5\% while for the USA economy declined by $8 \%$.

All data for Population (Fig.S5) are retrieved from World Bank Open Data ${ }^{9}$.The population in the USA increases linearly, while Germany's population remains approximately constant, with a slightly decrease from 2009 to 2011. An upward trend in income is observed in both countries, similar to GDP (Fig.S6).

Summarizing all the above-mentioned facts, Table 2 depicts the physiology of the two economies and the analogy of their key variables for the years 2000 (a) and 2017 (b).

\begin{tabular}{c|ccc} 
a. Key variables - 2000 & USA & Germany & USA/Germany \\
\hline $\begin{array}{c}\text { Energy Consumption } \\
(\text { Mtoe })\end{array}$ & $1.546,3$ & 231,4 & 6,7 \\
\hline $\begin{array}{c}\mathbf{C O}_{2} \text { emissions } \\
\left(\mathrm{MtCO}_{2}\right)\end{array}$ & $3.411,8$ & 515,5 & 6,6 \\
\hline $\begin{array}{c}\text { GDP } \\
(\text { million 2010 US\$) }\end{array}$ & $12.620 .268,4$ & $3.118 .322,5$ & 4,0 \\
\hline $\begin{array}{c}\text { Population } \\
\text { (million people) }\end{array}$ & 282,2 & 82,2 & 3,4 \\
\hline $\begin{array}{c}\text { Income } \\
(2010 \text { US } \$)\end{array}$ & $44.721,0$ & $37.935,8$ & 1,2 \\
\hline
\end{tabular}

333

\begin{tabular}{c|ccc} 
b. Key variables -2017 & USA & Germany & USA/Germany \\
\hline $\begin{array}{c}\text { Energy Consumption } \\
(\text { Mtoe })\end{array}$ & $1.520,5$ & 227,0 & 6,7 \\
\hline $\begin{array}{c}\mathbf{C O}_{2} \text { emissions } \\
\left(\mathrm{MtCO}_{2}\right)\end{array}$ & $3.163,3$ & 447,6 & 7,1 \\
\hline $\begin{array}{c}\text { GDP } \\
(\text { million 2010 US\$) }\end{array}$ & $17.348 .626,6$ & $3.878 .004,0$ & 4,5 \\
\hline $\begin{array}{c}\text { Population } \\
(\text { million people })\end{array}$ & 325,1 & 82,7 & 3,9 \\
\hline $\begin{array}{c}\text { Income } \\
(2010 \text { US\$) }\end{array}$ & $53.364,0$ & $46.892,4$ & 1,1 \\
\hline
\end{tabular}

Table 2. The physiology of the USA and German economies for the years 2000 (a) and 2017 (b).

Although the aggregate energy consumption for the two economies remains stable (USA/Germany $=6.7$ ), the respective analogy for $\mathrm{CO}_{2}$ emissions increased from 6.6 to 7.1

${ }^{9}$ https://data.worldbank.org 
(2000-2017). This reflects that German policy measures for decarbonization of the economy are more effective than those of the USA.

In order to examine further the efficiency of the existing environmental policies for both economies, we set a Baseline scenario. For the case of Germany, we attempt to forecast the evolution of $\mathrm{CO}_{2}$ emissions from 2018 to 2030. The years 1990 and 2030 are the landmarks of the German climate policy. By using historical data for the years 2000-2017, we estimate the average annual rate of $\mathrm{CO}_{2}$ emissions (- $\left.0.75 \%\right)$ according with the following formulae:

$$
\text { Average annual rate of } \mathrm{CO}_{2} \text { emissions }=\frac{\left.\sum_{1}^{\mathrm{N}} \text { (annual } \% \text { change of } \mathrm{CO}_{2} \text { emissions }\right)}{\mathrm{N}}
$$

where $N$ is the number of years.

We assume this rate will persist for the years 2018-2030 and the results are shown to Fig.1a.

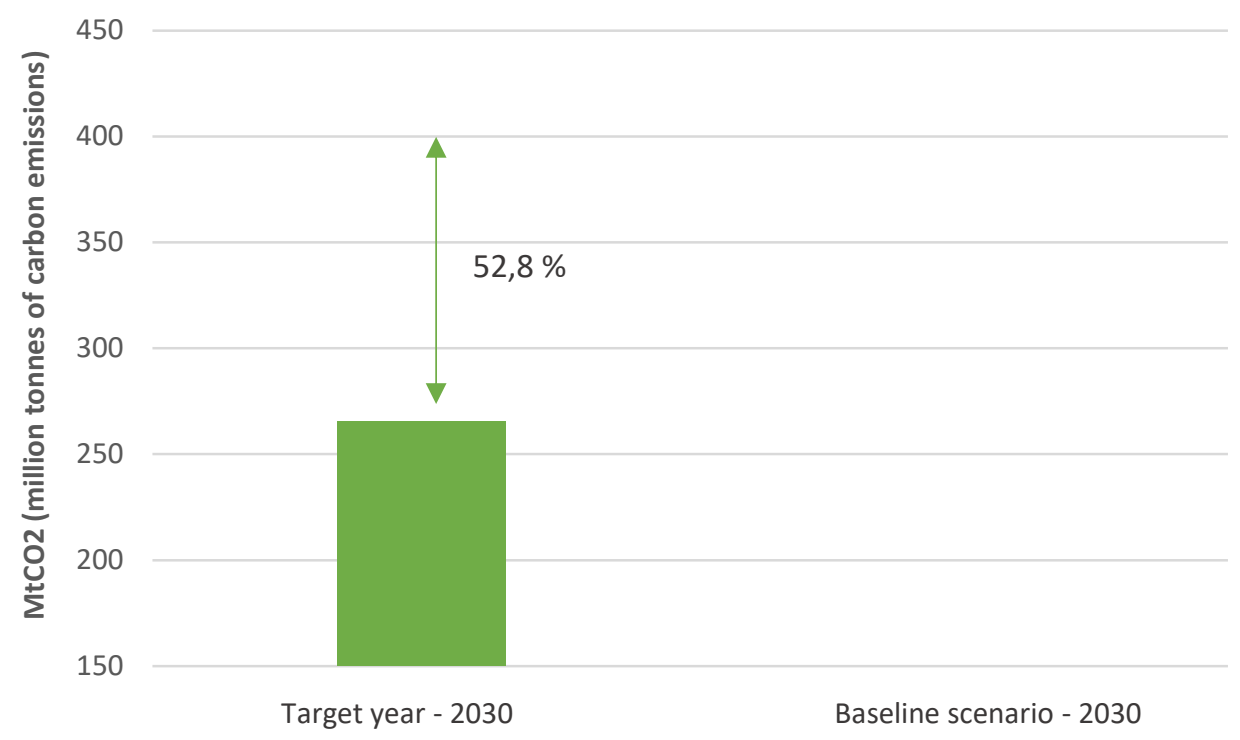

Fig. 1a. Forecast results of the German $\mathrm{CO}_{2}$ emissions.

Adopting the same rationale, we forecast the evolution of $\mathrm{CO}_{2}$ emissions from 2018 to 2025 for the case of the USA. The average annual rate of change of $\mathrm{CO}_{2}$ emissions for the years 2018-2025 is equal to $-0.41 \%$, as defined by using historical data for the years $2000-2017$. The results for the $\mathrm{CO}_{2}$ emissions levels are demonstrated in Fig.1b. 


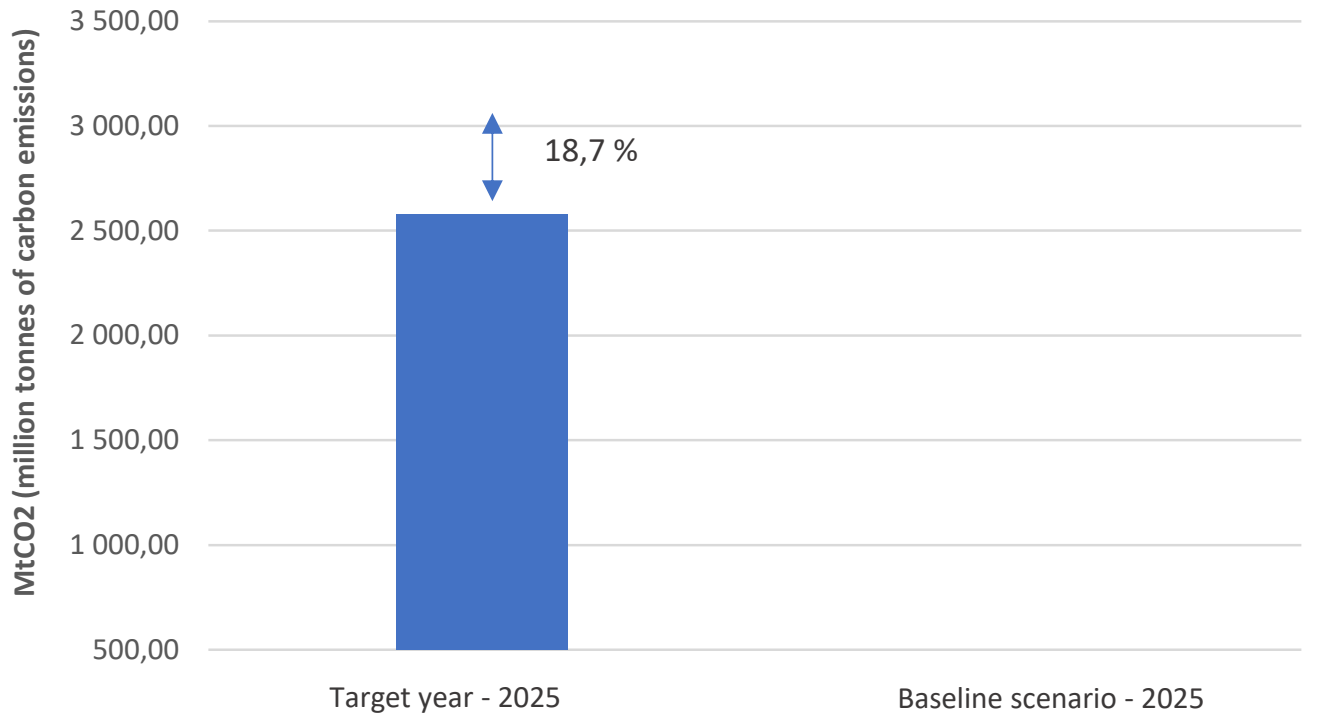

The forecast results imply that $\mathrm{CO}_{2}$ emissions targets cannot be achieved under the baseline scenario for both economies: the German economy remains apart by $52.8 \%$ from the 2030 optimistic target, while the USA by $18.7 \%$ from the 2025 emission levels.

\subsection{Data for Structural Analysis in the USA and Germany}

In this subsection we perform a descriptive structural analysis for the USA and Germany economy. The following sectors are selected according to the EIA (U.S Energy Information Administration, 2020a) approach:

- Residential sector: Utilities - Household consumption

- Commercial sector: Private Services (Financial, Business, Educational, Health \& Food Services) \& Government Services

○ Industrial sector: Agriculture, Mining, Construction \& Manufacturing

○ Transportation sector: Transportation \& Warehousing

Fig.2 presents the Energy Consumption per sector for Germany (2a) and the USA (2b). The 


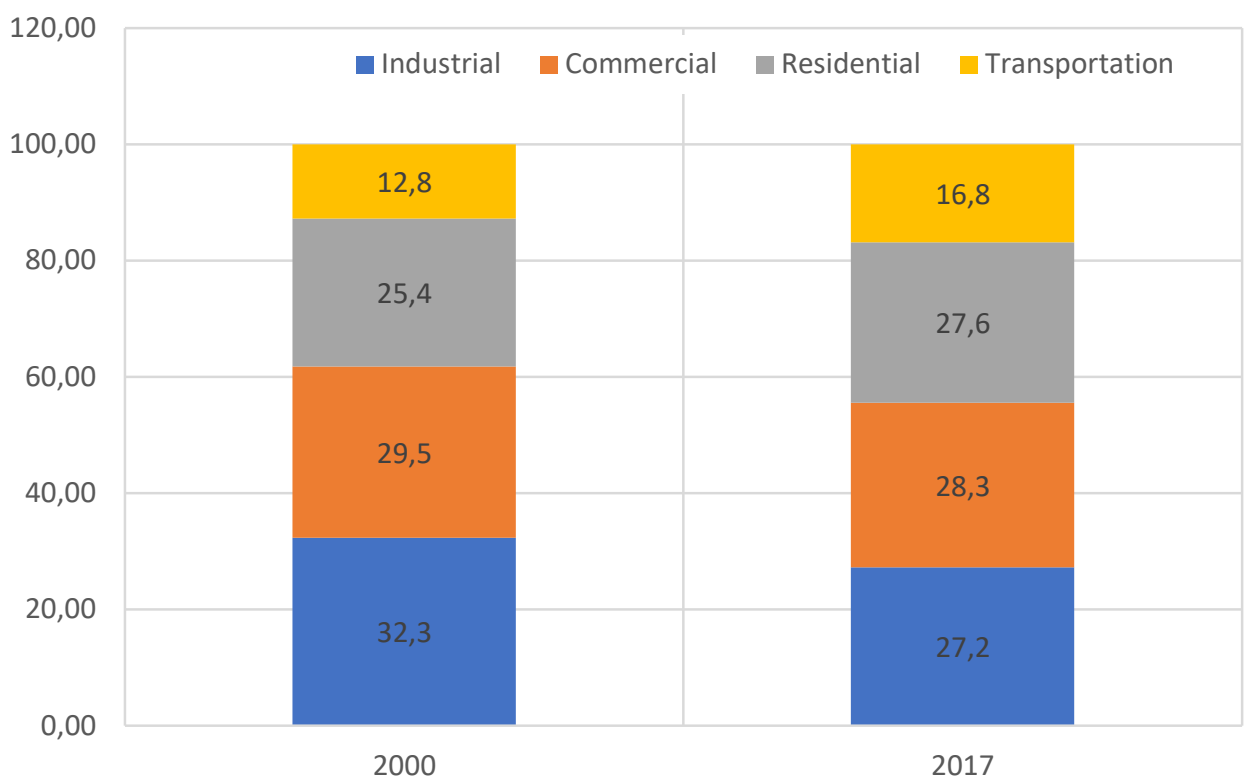

408

409

Fig. 2a. Percentage (\%) of Energy Consumption for the sectors of the German economy (2000 and 2017)

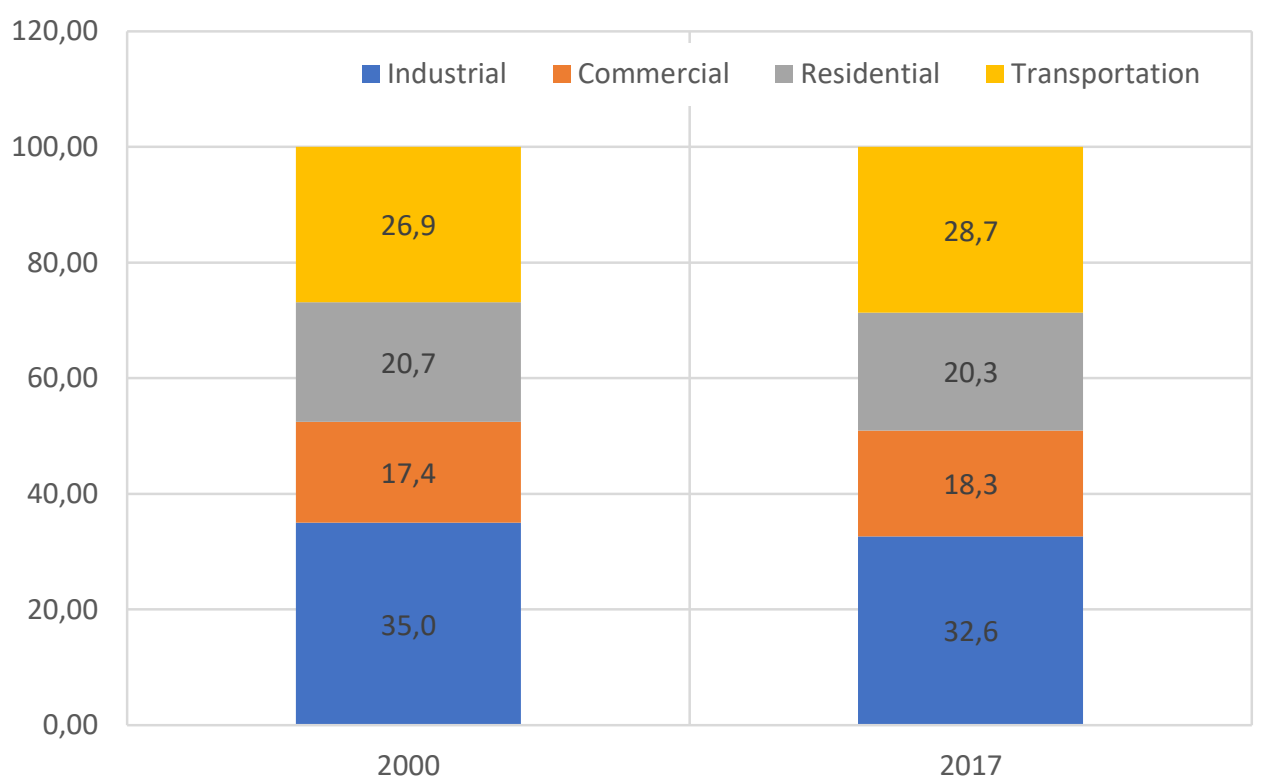

Fig. 2b. Percentage (\%) of Energy Consumption for the sectors of the USA economy (2000 and 2017)

In 2000 , the Industrial sector is responsible for $32.3 \%$ of the energy use of the German economy. After 17 years, the Industrial sector is responsible for $27.2 \%$ of the energy use. For the USA, the share of industrial sector has a reduction of $2.4 \%$ (2000-2017). 
Fig. 3 depicts the GDP per sector for Germany (3a) and the USA (3b). The data are retrieved from Eurostat (European Commission, 2020b) and BEA (2020), respectively.

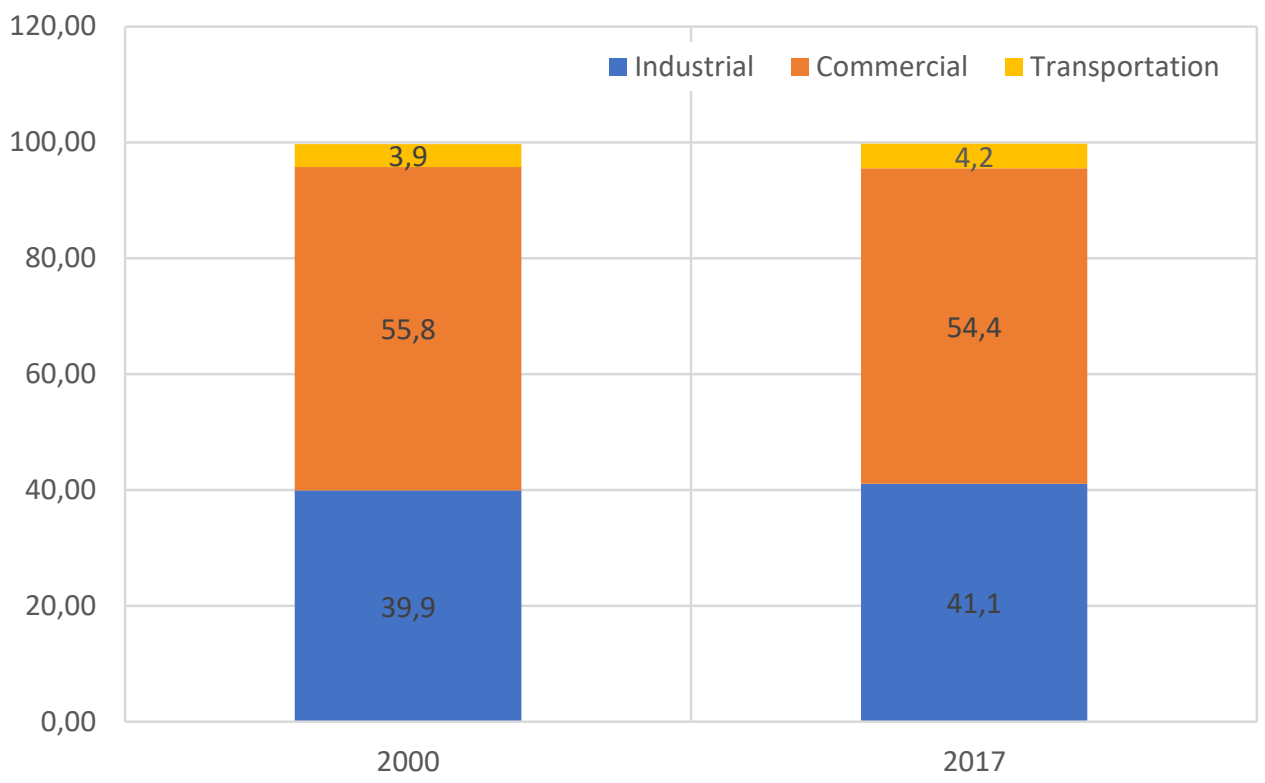

Fig. 3a. Percentage (\%) of GDP for the sectors of the German economy (2000 and 2017)

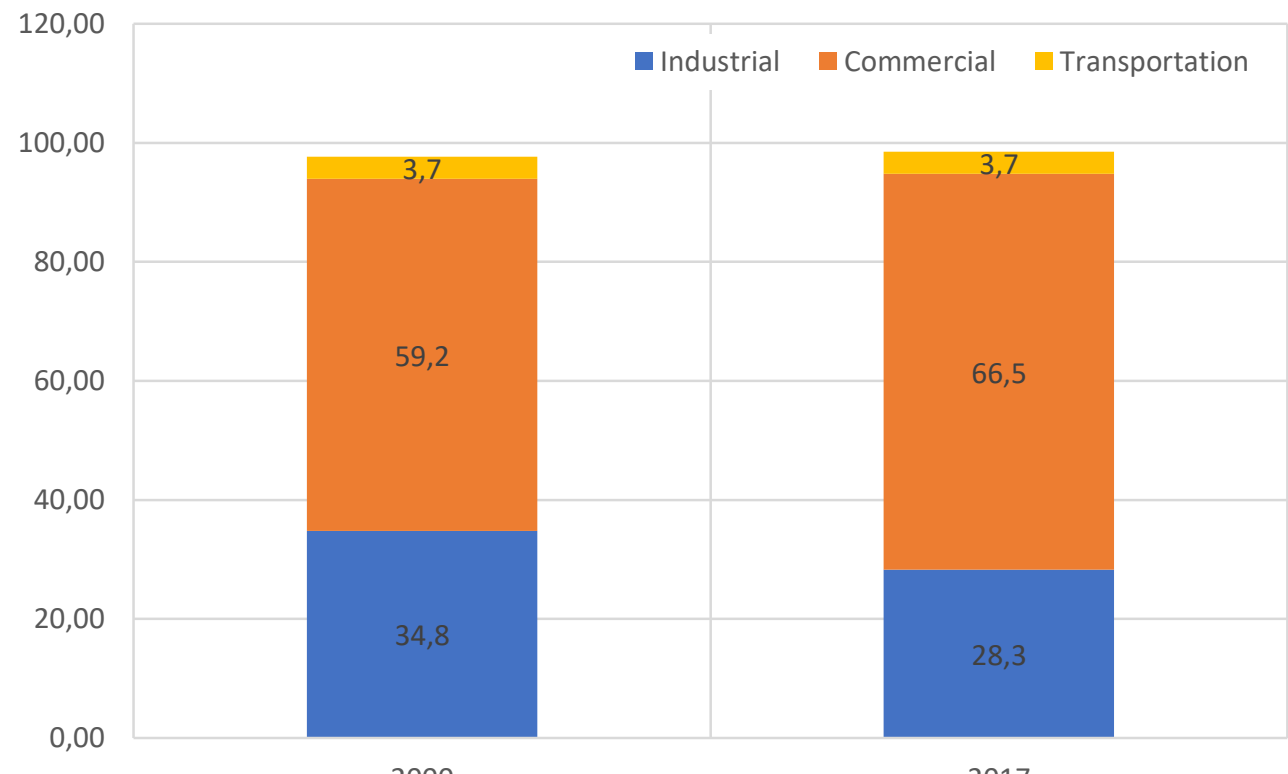

Fig. 3b. Percentage (\%) of GDP for the sectors of the USA economy (2000 and 2017)

Figure 3a denotes that the structure of the German economy remains almost stable during the study period. Regarding the structure of the USA economy, the Commercial sector contributes the most value added in 2000 and 2017, while the GDP share for Industrial sector is down over $6.5 \%$ from 2000 to 2017 . These changes demonstrate the USA's "turning point" as a service-oriented economy in accordance with the relevant literature (Yao et al., 2015; van Neuss, 2019). The share of residential sector is negligible for the two economies. 
Fig.4a presents the Energy Intensity per sector for the German economy.

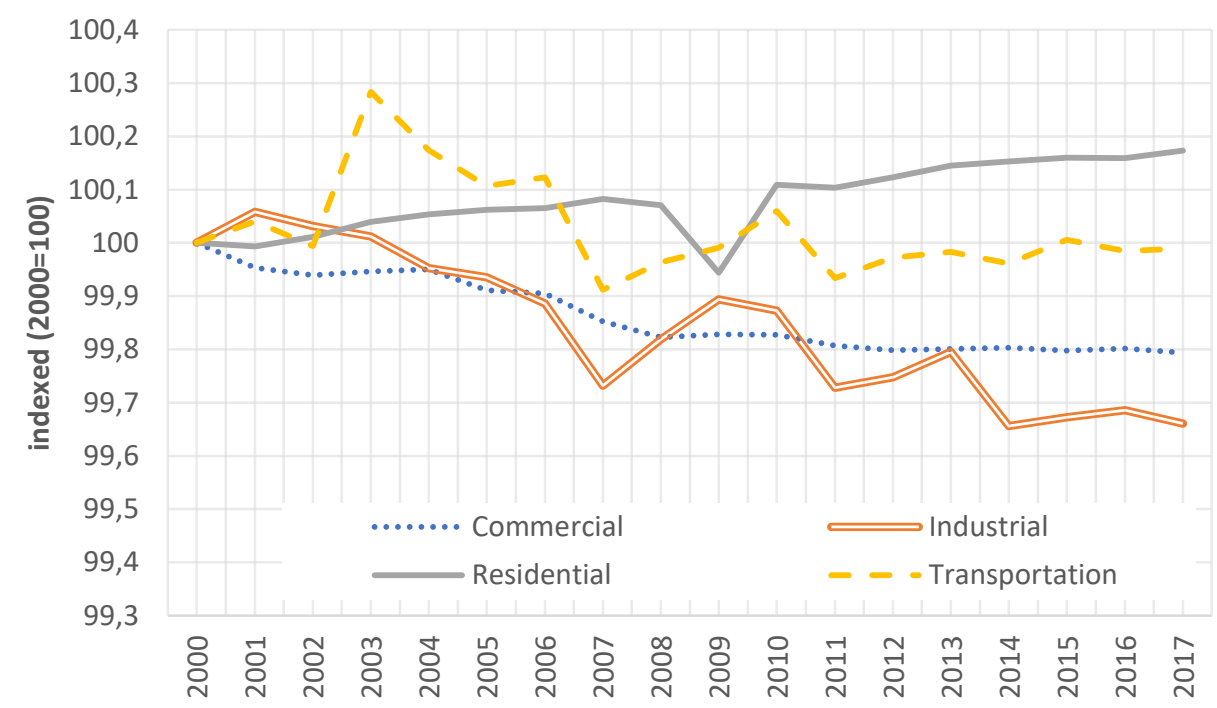

Fig.4a. Energy Intensity per sector in Germany from 2000 to 2017 (indexed 2000=100).

As can be seen, energy intensity trends for Commercial sector have been gradually decreasing since 2000. The energy intensity for the Industrial sector presents fluctuations with a total decreasing trend (-34\% in the period 2000-2017), underlining the deindustrialization effect.

Fig.4b shows the Energy Intensity per sector for the USA economy.

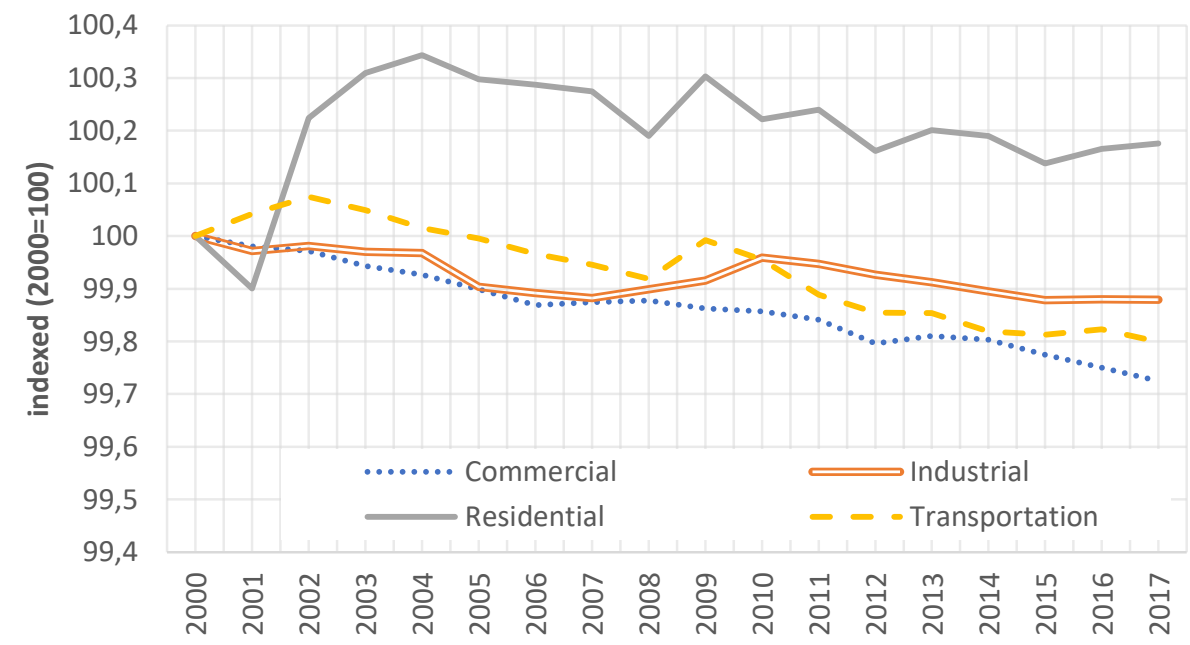

Fig.4b. Energy Intensity per sector in the USA from 2000 to 2017 (indexed 2000=100).

Decreases in the energy intensity for Transportation and Industrial sectors denote energy efficiency improvements and structural changes in the economy (Tol et al., 2009; Herrendorf et al., 2014; van Neuss, 2019). 


\section{Results and Discussion}

\subsection{Decoupling Analysis of energy-related $\mathrm{CO}_{2}$ emissions from economic growth}

457 In this section we attempt to interpret the connection between economic growth and energyrelated $\mathrm{CO}_{2}$ emissions by means of a decoupling analysis.

459

460

461

462

463

464

465

466

467

468

469

470

471

472

473

EI as the key index of the link between economy and energy consumption, is often used to assess the energy efficiency of a particular economy, indicating how well the economy converts energy into monetary output (Martínez et al.,2019). Fig.5a depicts the trends of energy intensity indexes: $\mathrm{EI}_{\mathrm{GDP}}$ and $\mathrm{EI}_{\mathrm{Inc}}$. The declining trends of $\mathrm{EI}$ indexes demonstrate the so-called decoupling effect denoting a gradual delinkage of growth from energy use. In addition, the $\mathrm{EI}_{\text {Inc. }}$ index denotes a weaker decoupling effect in the USA than Germany. The trend is declining for both countries, with relatively small fluctuations.
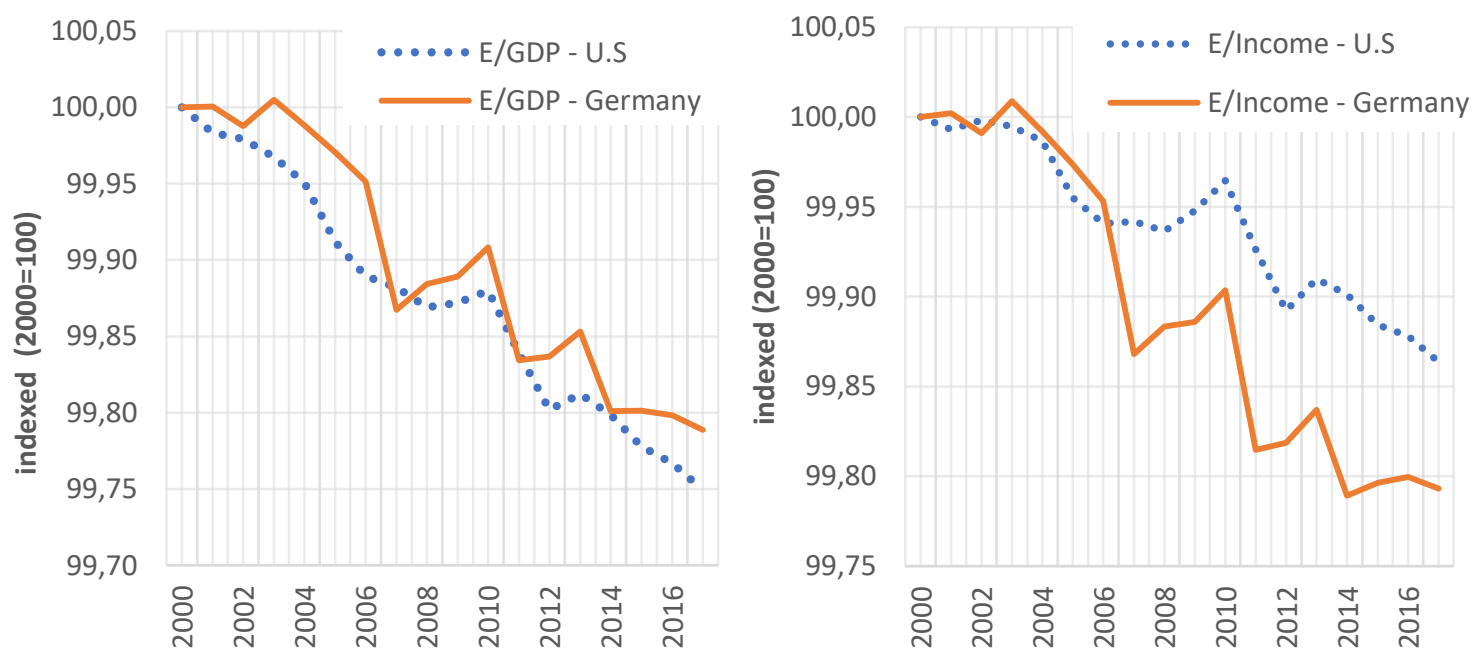

Fig.5a. Energy Intensity Indexed for the USA and Germany from 2000 to 2017 (indexed 2000=100).

Fig. $5 b$ shows the trends of the carbon intensity indexes: $\mathrm{CI}_{\mathrm{GDP}}$ and $\mathrm{CI}_{\mathrm{Inc}}$, for the economies of the USA and Germany.
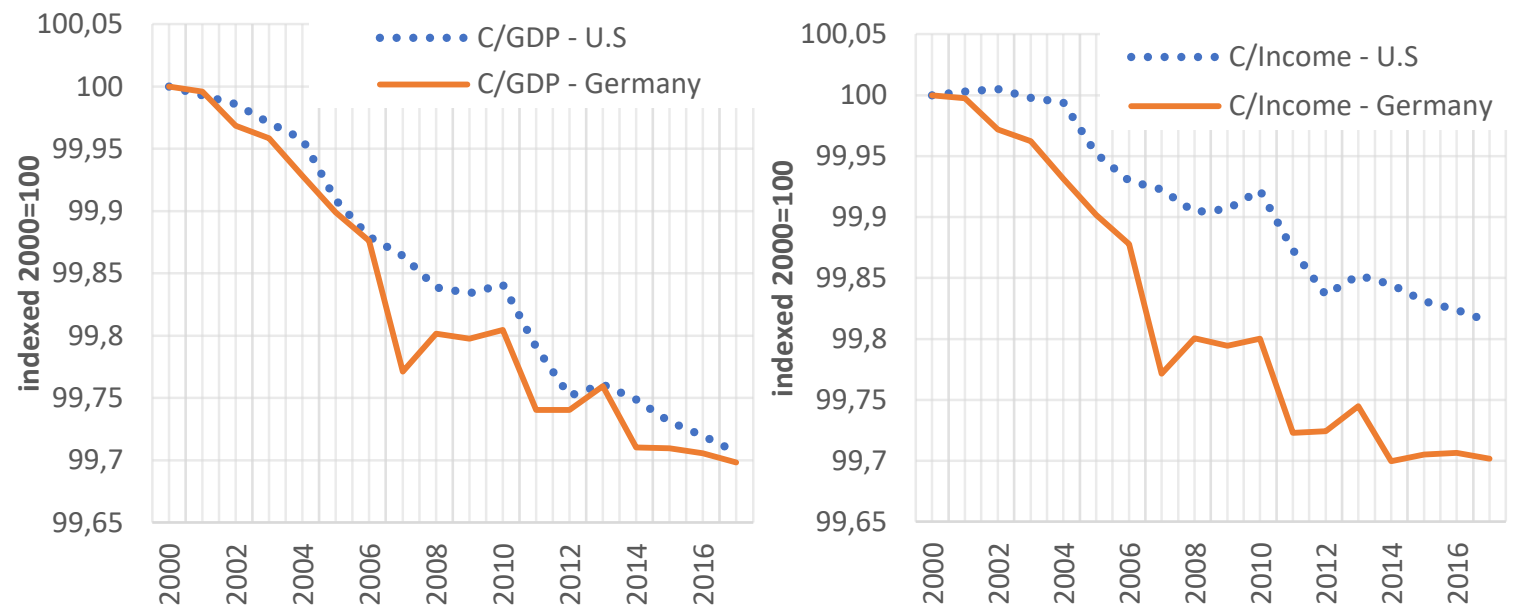

Fig. 5b. Carbon Intensity indexes for the USA and Germany from 2000 to 2017. 
477 The declining trends of $\mathrm{CI}_{\text {Inc }}$ index follow similar evolution trajectories with the $\mathrm{EI}_{\text {Inc }}$ index, 478 denoting also a weaker decoupling effect in the USA than Germany. Although, differentiations occur on the evolution of $\mathrm{CI}_{\mathrm{GDP}}$ index, denoting a stronger decoupling in Germany than the USA.

Tables $3 \mathrm{a}$ and $3 \mathrm{~b}$ depict the $\mathrm{EI}_{\mathrm{GDP}}, \mathrm{EI}_{\mathrm{Inc}}, \mathrm{CI}_{\mathrm{GDP}}$ and $\mathrm{CI}_{\mathrm{Inc}}$ indexes for Germany and the USA, respectively. We also calculate the percentage change of the relevant indexes from 2000 to 2017.

\begin{tabular}{ccccc}
\hline Year & $\boldsymbol{E I}_{\boldsymbol{G D P}}$ & $\boldsymbol{E I}_{\boldsymbol{I n c}}$ & $\boldsymbol{C I}_{\boldsymbol{G D P}}$ & $\boldsymbol{C I}_{\boldsymbol{I n c}}$ \\
\hline 2000 & 0,0742 & 0,0061 & 0,000165 & 0,013592 \\
2017 & 0,0585 & 0,0048 & 0,000115 & 0,009540 \\
$2000-2017(\%)$ & $-21,16 \%$ & $-21,31 \%$ & $-30,19 \%$ & $-29,81 \%$ \\
\hline
\end{tabular}

486

487

488

489

490

491

492

493

494

495

496

497

498

499

500

501

502

503

504

505

506

507

508

509

510 Tables $4 \mathrm{a}$ and $4 \mathrm{~b}$ presents the Decoupling states and the percentage changes of Carbon 511 Intensity Indexes for the Germany and the USA respectively.

Table 3a: Carbon intensity and energy intensity comparison for the economy of Germany.

\begin{tabular}{ccccc}
\hline Year & $\boldsymbol{E I}_{\boldsymbol{G D P}}$ & $\boldsymbol{E I}_{\boldsymbol{I n c}}$ & $\boldsymbol{C I}_{\boldsymbol{G D P}}$ & $\boldsymbol{C I}_{\boldsymbol{I n c}}$ \\
\hline 2000 & 0,1225 & 0,0174 & 0,000136 & 0,038468 \\
2017 & 0,0876 & 0,0151 & 0,000096 & 0,031327 \\
$2000-2017(\%)$ & $-28,49 \%$ & $-13,22 \%$ & $-29,33 \%$ & $-18,56 \%$ \\
\hline
\end{tabular}

Table 3b: Carbon intensity and energy intensity comparison for the economy of the USA.

Table 3a indicates an important difference between carbon intensity indexes and energy intensity indexes; the percentage changes of $\mathrm{CI}_{\mathrm{GDP}}$ and $\mathrm{CI}_{\mathrm{Inc}}$ are higher than the respective of the $\mathrm{EI}_{\mathrm{GDP}}$ and $\mathrm{EI}_{\mathrm{Inc}}$. This denotes that Germany is less carbon-intensive economy than energyintensive.

According to Table $3 \mathrm{~b}$, the $\mathrm{CI}_{\mathrm{GDP}}$ and $\mathrm{EI}_{\mathrm{GDP}}$ indexes has similar percentage changes through the period 2000-2017 for the USA, in contrast with the income-based indexes. As can be concluded, GDP-based indexes for the case of the USA indicate no significant differentiation between the two types of intensities and tend to decrease considerably faster than incomebased indexes.

The decoupling effect is caused by declining carbon intensity (Wu et al., 2005; Wang et al., 2005). We further investigate the decoupling effect following the categorization proposed by various researchers (Watson, 2014; Bachtrögler, 2016). In this concept we examine the impact of financial crisis on the relationship among the energy-environment and economy. The study period is divided into three phases:

a. the period before the Great Recession (2000-2007)

b. the period of the Great Recession (2007-2013)

c. the period after the Great Recession (2013-2017)

512

513

\begin{tabular}{lllllll} 
Time & DI $_{\text {GDP }}$ & CI $_{\text {GDP }}$ & Decoupling & DI Inc $_{\text {In }}$ & CI Inc $_{\text {In }}$ & Decoupling \\
\hline
\end{tabular}




\begin{tabular}{|c|c|c|c|c|c|c|}
\hline Period & & $(\%)$ & state & & $(\%)$ & state \\
\hline & -156 & $-2289 \%$ & $\begin{array}{c}\text { Strong } \\
\text { decoupling }\end{array}$ & -157 & $-2284 \%$ & $\begin{array}{c}\text { Strong } \\
\text { decoupling }\end{array}$ \\
\hline & & & Weak & & & Weak \\
\hline $2007-2013$ & 0,60 & $-1,52 \%$ & decoupling & 0,39 & $-3,46 \%$ & decoupling \\
\hline 2013-2017 & 0,02 & $-8,07 \%$ & $\begin{array}{c}\text { Weak } \\
\text { decoupling }\end{array}$ & 0,02 & $-5,78 \%$ & $\begin{array}{c}\text { Weak } \\
\text { decoupling }\end{array}$ \\
\hline \multicolumn{7}{|c|}{ Table 4a. Decoupling Analysis of energy-related $\mathrm{CO}_{2}$ emissions for 2000-2017 in Germany. } \\
\hline $\begin{array}{l}\text { Time } \\
\text { Period }\end{array}$ & $\mathbf{D I}_{\text {GDP }}$ & $\begin{array}{c}\mathbf{C I}_{\text {GDP }} \\
(\%)\end{array}$ & $\begin{array}{c}\text { Decoupling } \\
\text { state }\end{array}$ & $\mathbf{D I}_{\text {Inc }}$ & $\begin{array}{c}\mathbf{C I}_{\text {Inc }} \\
(\%)\end{array}$ & $\begin{array}{c}\text { Decoupling } \\
\text { state }\end{array}$ \\
\hline $2000-2007$ & $-0,01$ & $-13,59 \%$ & $\begin{array}{c}\text { Strong } \\
\text { decoupling }\end{array}$ & $-0,02$ & $-7,75 \%$ & $\begin{array}{c}\text { Strong } \\
\text { decoupling }\end{array}$ \\
\hline 2007-2013 & $-3,04$ & $-11,95 \%$ & $\begin{array}{c}\text { Strong } \\
\text { decoupling } \\
\text { Weak }\end{array}$ & 5,18 & $-7,61 \%$ & $\begin{array}{c}\text { Expansive } \\
\text { decoupling } \\
\text { Weak }\end{array}$ \\
\hline $2013-2017$ & 0,23 & $-7,12 \%$ & decoupling & 0,33 & $-4,45 \%$ & decoupling \\
\hline
\end{tabular}

517

Table 4b. Decoupling Analysis of energy-related $\mathrm{CO}_{2}$ emissions for 2000-2017 in the USA.

More specifically, in the period before the financial crisis we observe a strong decoupling state for both economies. For the case of Germany, the shift from strong to weak decoupling state happens in the years of the financial crisis $\left(\mathrm{DI}_{\mathrm{GDP}}=0.6 \& \mathrm{DI}_{\mathrm{Inc}}=0.39,2007-2013\right)$ and remains in that state $\left(\mathrm{DI}_{\mathrm{GDP}}=0.02 \& \mathrm{DI}_{\mathrm{Inc}}=0.02,2013-2017\right)$, while the USA turns into weak decoupling state after $2013\left(\mathrm{DI}_{\mathrm{GDP}}=0.23 \& \mathrm{DI}_{\mathrm{Inc}}=0.33,2013-2017\right)$. The financial crisis in the USA (2007-2013), resulting in negative $\mathrm{CO}_{2}$ emission annual growth rates, at $-6 \%$ and $-4 \%$ in 2009 and 2012, respectively. These were the lowest rates from 2000 to 2017, indicating that $\mathrm{CO}_{2}$ emissions declined in line with economic recession (U.S Energy Information Administration, 2020b).

\subsection{Application of LMDI technique for $\mathrm{DA}$ of energy-related $\mathrm{CO}_{2}$ emissions in Germany and the USA.}

\subsubsection{Results of Additive LMDI Decomposition Analysis}

We apply a set of LMDI decomposition techniques to interpret the evolution of energyrelated $\mathrm{CO}_{2}$ emissions, the dependent variable of the current study. With this approach we can quantify the effect of each decomposition factor on the evolution of $\mathrm{CO}_{2}$ emissions.

541

542

543

544

545

546

The results of the decomposition analysis with additive LMDI technique are depicted in Tables $5 \mathrm{a}$ and $5 \mathrm{~b}$ for Germany and the USA, respectively. 
547

548

549

550

\begin{tabular}{c|ccccc}
\hline $2000-2001$ & 7,86 & 0,87 & $-2,36$ & 0,22 & 6,59 \\
$2001-2002$ & $-1,89$ & 0,86 & $-7,73$ & $-6,65$ & $-15,40$ \\
$2002-2003$ & $-3,87$ & 0,28 & $-13,94$ & 8,69 & $-8,85$ \\
$2003-2004$ & 5,94 & $-0,11$ & $-7,59$ & $-8,17$ & $-9,93$ \\
$2004-2005$ & 3,74 & $-0,27$ & $-6,78$ & $-8,69$ & $-12,01$ \\
$2005-2006$ & 18,46 & $-0,54$ & $-2,64$ & $-9,60$ & 5,68 \\
$2006-2007$ & 14,10 & $-0,61$ & $-16,19$ & $-42,40$ & $-45,11$ \\
$2007-2008$ & 5,13 & $-0,85$ & 8,70 & 8,68 & 21,66 \\
$2008-2009$ & $-24,91$ & $-1,12$ & $-4,69$ & 2,38 & $-28,34$ \\
$2009-2010$ & 18,71 & $-0,68$ & $-5,49$ & 9,37 & 21,92 \\
$2010-2011$ & 25,19 & $-8,19$ & 0,76 & $-37,53$ & $-19,77$ \\
$2011-2012$ & 1,00 & 0,81 & $-1,24$ & 1,29 & 1,86 \\
$2012-2013$ & 0,68 & 1,20 & 2,62 & 8,54 & 13,03 \\
$2013-2014$ & 7,80 & 1,82 & $-1,83$ & $-27,45$ & $-19,67$ \\
$2014-2015$ & 3,70 & 3,73 & $-0,42$ & 0,16 & 7,17 \\
$2015-2016$ & 6,12 & 3,53 & $-0,86$ & $-1,75$ & 7,04 \\
$2016-2017$ & 9,16 & 1,66 & 0,64 & $-5,33$ & 6,13 \\
\hline $\mathbf{2 0 0 0 - 2 0 1 7}$ & $\mathbf{9 6 , 9 3}$ & $\mathbf{2 , 4 0}$ & $\mathbf{- 5 9 , 0 6}$ & $\mathbf{- 1 0 8 , 2 5}$ & $\mathbf{- 6 7 , 9 8}$ \\
\hline
\end{tabular}

Table 5a. Factor Decomposition Analysis (Additive LMDI) for Germany, 2000-2017 (unit: $\mathrm{MtCO}_{2}$ ).

\begin{tabular}{c|ccccc}
\hline Year & $\Delta C_{\text {inc }}$ & $\Delta C_{\text {pop }}$ & $\Delta C_{\text {str }}$ & $\Delta C_{\text {int }}$ & $\Delta C_{\text {tot }}$ \\
\hline $2000-2001$ & $-34,59$ & 33,64 & 33,69 & $-57,53$ & $-24,79$ \\
$2001-2002$ & $-9,37$ & 31,41 & $-10,28$ & $-14,05$ & $-2,28$ \\
$2002-2003$ & 47,10 & 29,19 & $-11,74$ & $-41,14$ & 23,42 \\
$2003-2004$ & 91,18 & 31,89 & 14,12 & $-60,14$ & 77,05 \\
$2004-2005$ & 102,00 & 31,90 & $-37,27$ & $-144,17$ & $-47,54$ \\
$2005-2006$ & 42,52 & 32,97 & $-27,77$ & $-85,07$ & $-37,35$ \\
$2006-2007$ & 33,60 & 32,37 & $-31,44$ & $-28,23$ & 6,29 \\
$2007-2008$ & $-76,08$ & 31,53 & $-49,09$ & $-49,94$ & $-143,58$ \\
$2008-2009$ & $-208,04$ & 27,72 & $-29,31$ & 10,57 & $-199,06$ \\
$2009-2010$ & 74,53 & 25,93 & $-1,47$ & 28,26 & 127,25 \\
$2010-2011$ & 44,78 & 22,71 & $-44,04$ & $-148,98$ & $-125,52$ \\
$2011-2012$ & 56,38 & 22,21 & $-16,93$ & $-136,29$ & $-74,63$ \\
$2012-2013$ & 41,90 & 21,08 & $-1,86$ & 38,80 & 99,93 \\
$2013-2014$ & 70,07 & 22,85 & 1,92 & $-52,32$ & 42,50 \\
$2014-2015$ & 52,33 & 23,11 & 8,49 & $-82,79$ & 1,15 \\
$2015-2016$ & 33,92 & 22,70 & $-5,40$ & $-44,70$ & 6,53 \\
$2016-2017$ & 58,61 & 20,19 & 15,70 & $-72,30$ & 22,20 \\
\hline $\mathbf{2 0 0 0 - 2 0 1 7}$ & $\mathbf{4 2 0 , 8 4}$ & $\mathbf{4 6 3 , 4 0}$ & $\mathbf{- 1 9 2 , 6 8}$ & $\mathbf{- 9 4 0 , 0 1}$ & $\mathbf{- 2 4 8 , 4 4}$ \\
\hline
\end{tabular}

551

552

553

554

Table 5b. Factor Decomposition Analysis (Additive LMDI) for the USA, 2000-2017 (unit: $\mathrm{MtCO}_{2}$ ). As shown in Table 5a, in Germany, the income effect was the primary factor contributing to the increase of $\mathrm{CO}_{2}$ emissions during 2000-2017, with the exception of the 2008-2009 time 
period. The $\mathrm{CO}_{2}$ emissions cumulatively increased by $96.93 \mathrm{MtCO}_{2}$ because of income growth. The effects of energy intensity $\left(-108.25 \mathrm{MtCO}_{2}\right)$ and energy structure $(-59.06$ $\left.\mathrm{MtCO}_{2}\right)$ are the critical factors that induce the decrease of emissions during 2000-2017. The federal government (2014) adopted measures for the increase of renewable shares in power generation, modernization of fossil fuel power plants and the development of more cogeneration plants (IEA, 2020b). Furthermore, the share of Renewables presents 3.2 times increase from 2000 to 2017 (Fig.S1), contributed to the mitigation of $\mathrm{CO}_{2}$ emissions. The impact of population effect on $\mathrm{CO}_{2}$ emissions $\left(2.4 \mathrm{MtCO}_{2}\right)$ is positive but weak.

Table $5 \mathrm{~b}$ presents the results of the time series LMDI technique for the USA. The first influencing factor to rise emissions is the population effect. This factor eventually contributed to an increase in emissions of $463.40 \mathrm{MtCO}_{2}$ from 2000 to 2017. The income effect exhibits substantial variations during the examined period, leading to an overall positive contribution to the increase or energy-related $\mathrm{CO}_{2}$ emissions $\left(420.84 \mathrm{MtCO}_{2}, 2000-2017\right)$. The USA has a mean annual increase in income about $0.8 \%$. The energy intensity effect was the most critical factor decreasing $\mathrm{CO}_{2}$ emissions. The cumulative effect of energy intensity is near to $-940 \mathrm{Mt}$ $\mathrm{CO}_{2}$, while the total change of emissions is $-248.44 \mathrm{MtCO}_{2}$. Moreover, changes in the energy structure played a significant role in decreasing $\mathrm{CO}_{2}$ emissions (-192.68 $\left.\mathrm{MtCO}_{2}, 2000-2017\right)$. The energy mix marked an importance swift from coal (-48\%) to Renewables $(+52 \%)$ from 2000 to 2017.

\subsubsection{Comparative evaluation of Results}

In this sub-section we analyze the underlying driving forces responsible for the decrease of energy-related $\mathrm{CO}_{2}$ emissions, on a comparative basis. We apply the Multiplicative LMDI technique to explore and rank contributions of the decomposition factors (Figs.6a-6d).

\section{Income effect}

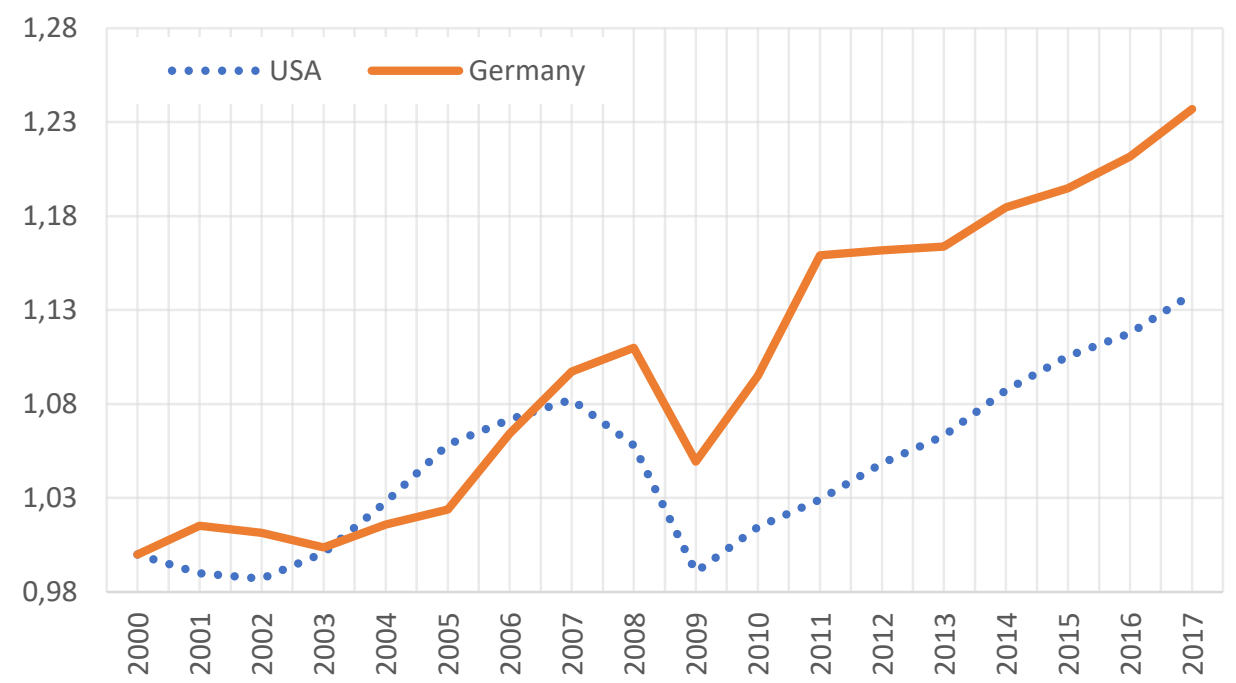

Fig. 6a. Change of energy-related $\mathrm{CO}_{2}$ emissions due to the Income Effect (Multiplicative LMDI)
} 
Fig.6b. Change of energy-related $\mathrm{CO}_{2}$ emissions due to the Energy Intensity Effect (Multiplicative

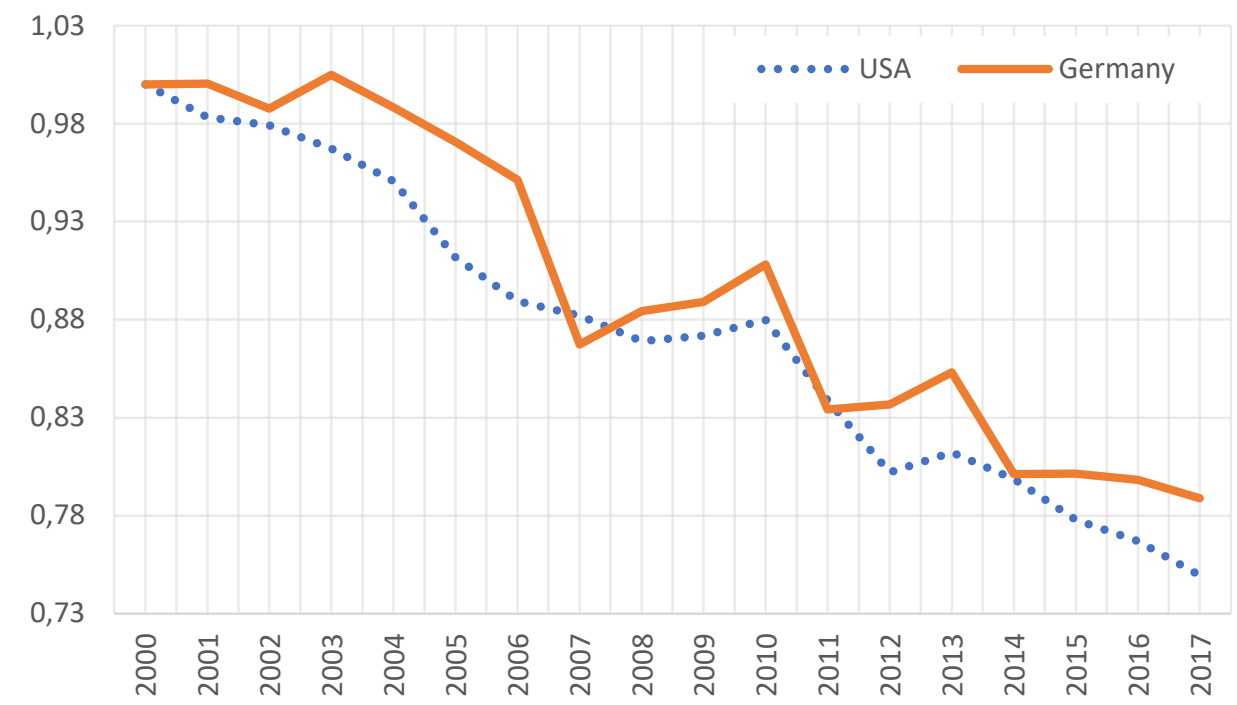
LMDI)

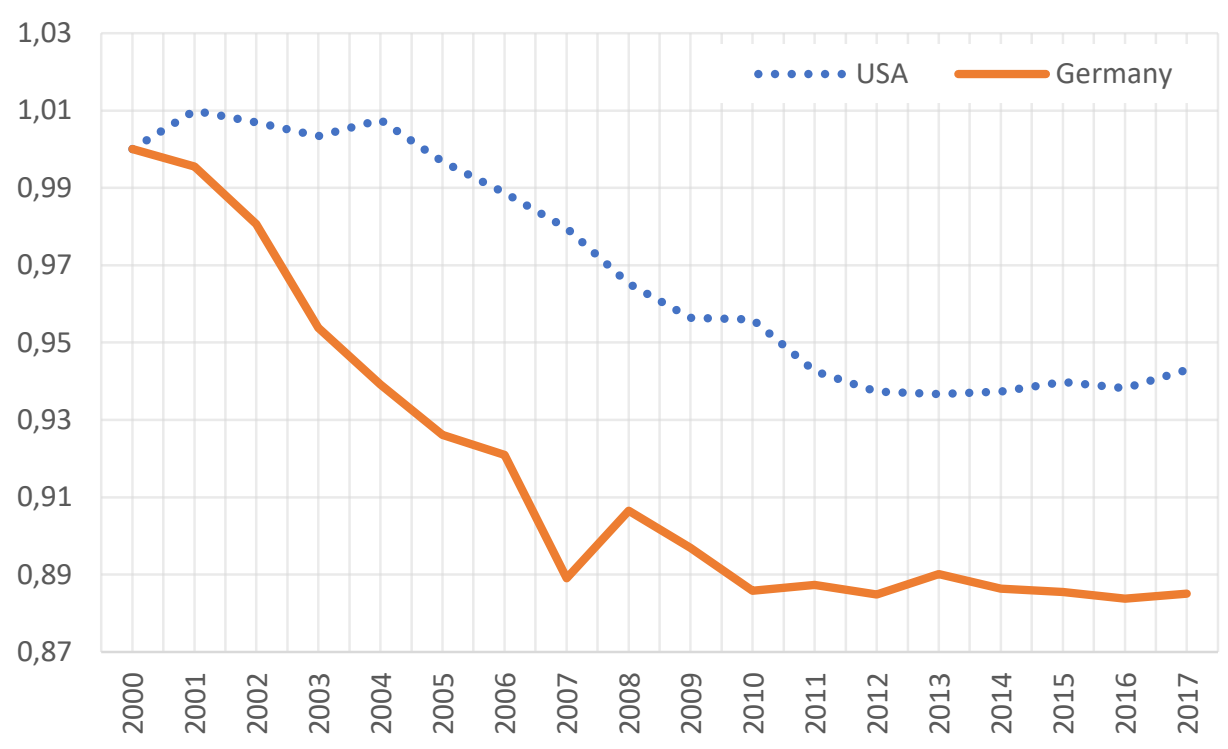

Fig. 6c. Change of energy-related $\mathrm{CO}_{2}$ emissions due to the Energy Structure Effect (Multiplicative $L M D I)$ 


\section{Population effect}

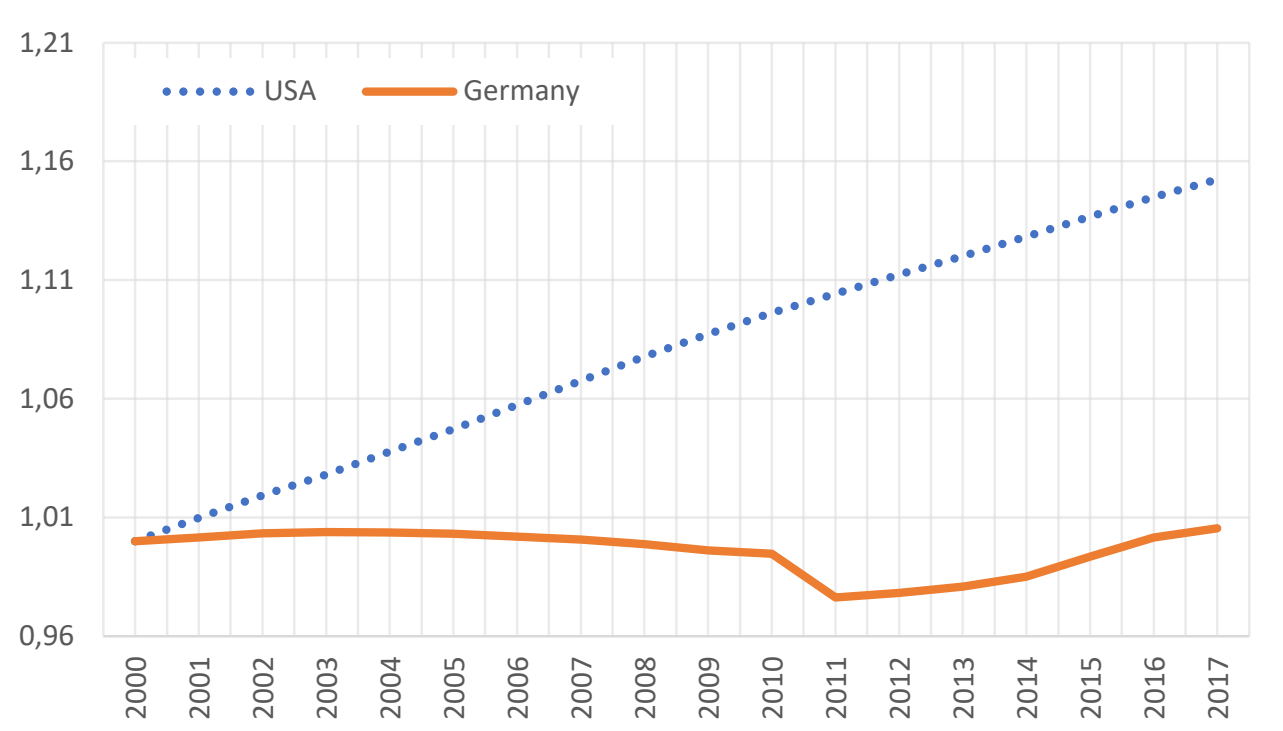

Fig. 6d. Change of energy-related $\mathrm{CO}_{2}$ emissions due to the Population Effect (Multiplicative LMDI)

The most crucial remarks are summarized below:

1. Total $\mathrm{CO}_{2}$ emissions reduced by $13.8 \%$ for German and by $7.3 \%$ for the USA, during 2000-2017. The decreasing trends of energy intensity and the substitution of carbonintensive coal and oil with renewable resources played positive roles in decreasing $\mathrm{CO}_{2}$ emissions. Although it is not clear the reasons behind the trends in energy intensity they are often attributed to technological advance and a swift of the economy towards services.

2. The energy intensity effect is negative for both economies: the trend for Germany presents a decrease by $21 \%$, where the trend for USA follows a decreasing trend by $25 \%$.

3. The energy structure effect influences $\mathrm{CO}_{2}$ emissions more in Germany $(-12 \%)$ than in the USA (-6\%) (Fig.6c).

4. The German income effect has greater positive contribution $(+24 \%)$ than the USA $(+14 \%)$.

5. The contribution of population effect, although positive in both economics, is infinitesimal in Germany ( $+0.5 \%)$ while strong in the USA (+15\%), (Fig. $6 \mathrm{~d})$.

\section{Conclusions}

The USA and German economies for the period 2000-2017 present an increasing GDP and Income, with the exception of 2007-2013. For the USA economy, the descriptive data analysis demonstrates the de-industrialization effect. Population increased $(15.2 \%)$ in the USA while remain stable in Germany.

A decoupling analysis indicate a smoother transition from strong to weak decoupling for the USA. The weak decoupling was found in both Germany and the USA in 2013-2017 denotes that these advanced economies should enhance relevant decoupling efforts in order to move towards to the pre-financial crisis decoupling states. Future decoupling efforts requires "cleaner" energy structure for both economies.

We employ LMDI additive and multiplicative techniques to identify the causal effects on the evolution of energy-related $\mathrm{CO}_{2}$ emissions. The crucial factor responsible for the decrease of 
$646 \mathrm{CO}_{2}$ emissions for both economies is energy intensity. Remarkably, the energy intensity of industrial sector is declined by $34 \%$ for the German economy and by $12 \%$ for the USA economy. This difference once combined with the relative deindustrialization of the USA induces some policy suggestions for the USA whose industrial sector presents a relatively bad emissions performance which induces an inferior $\mathrm{CO}_{2}$ reduction, almost half from those of Germany. Germany, although increased the share of the industrial sector, reduced more intensively $\mathrm{CO}_{2}$ emissions, mainly due to the decreasing EI of its industrial sector. This performance of the industrial sector of Germany combined with changes of the energy structure, offset the increased contribution of the income factor which had a much stronger compared to the USA's income.

656

657

658

659

660

661

662

663

664

665

666

667

668

669

670

\section{1}

672

673

674

675

676

677
The impact of the population has been strong in the USA however negligible in Germany. Taking into account that the population in Germany remains almost stable while there a substantially increasing population in the USA where $\mathrm{CO}_{2}$ emissions indicated a higher increase, there is a strong evidence that $\mathrm{CO}_{2}$ emissions are the outcome of processes and interactions both within economic and social systems. Natural, economic and social systems are coupled and interdependent. $\mathrm{CO}_{2}$ analysis, climate and energy policies ought to be envisaged as targeting the coupling of natural, economic and social systems and not isolated. An integrated consideration can be beneficial, effective and supporting in the pursuit of a sustainable economy. The adoption of an integrated approach in the design of energy policy may enrich potentials to reach the newly set ambitious climate targets which seems hard to achieve once past trends prevail, indicated by the baseline scenarios of the present study.

The future research effort should include complementary research on the causal relationship between the driving forces of $\mathrm{CO}_{2}$ emissions using an econometric analysis. This could provide a holistic approach for a sustainable future, denoting which variables are highly determined by others and leading to specific policy measures.

\section{Statements and Declarations}

Ethical Approval - Consent to Participate - Consent to Publish. This article does not contain any studies with human or animal subjects.

Authors Contributions. All authors contributed to the study conception and design. Material preparation, data collection and analysis were performed by EK, EH and KB. The first draft of the manuscript was written by EK and all authors commented on previous versions of the manuscript. All authors read and approved the final manuscript.

Funding. No funding was received to assist with the preparation of this manuscript.

Competing Interests. The authors have no competing interests to declare that are relevant to the content of this article.

Availability of data and materials. The raw data used in this study are available online at the relevant reference links. The data that support the findings of this study are available from the corresponding author, upon reasonable request. Supporting Material may be found online in the Supporting Information section at the end of this article. 
Ang BW (1999) Decomposition methodology in energy demand and environmental analysis. In: van den Bergh JCJM, editor. Handbook of environmental and resource economics. Cheltenham: Edward Elgar.

Bachtrögler J (2016) On the effectiveness of EU structural funds during the Great Recession: Estimates from a heterogeneous local average treatment effects framework. WU Vienna University of Economics and Business, Vienna. Department of Economics Working Paper No.230. https://www.wu.ac.at/economics/forschung/wp/

Bailey I, Rupp S (2004) Politics, Industry and the Regulation of Industrial GreenhouseGas emissions in UK and Germany. Eur Environ 14:235-250. https://doi.org/10.1002/eet.355

Baldwin JG, Wing IS (2013) The Spatiotemporal Evolution of U.S. Carbon Dioxide Emissions: Stylized Facts and Implications for Climate Policy. J of Regional Sci 53(4):672-689. https://doi.org/10.1111/jors.12028

Bhattacharyya SC, Matsumura W (2010) Changes in the GHG emission intensity in EU15: Lessons from a decomposition analysis. Energy 35(8):3315-3322. https://doi.org/10.1016/j.energy.2010.04.017

Bithas K, Kalimeris P (2013) Re-estimating the decoupling effect: Is there an actual transition towards a less energy-intensive economy? Energy 51:78-84. https://doi.org/10.1016/j.energy.2012.11.033

Bithas K, Kalimeris P (2018) Unmasking decoupling: Redefining the Resource Intensity of the Economy. Sci Total Environ 619-620:338-351. https://doi.org/10.1016/j.scitotenv.2017.11.061

Blodgett J, Parker L, and Industry Division (2002) Resources, Science, and Industry Division CRS Report for Congress, Global Climate Change: U.S. Greenhouse Gas Emissions — Status, Trends, and Projections.

Bureau of Economic Analysis (BEA) (2020) BEA Data. https://www.bea.gov/data/gdp

Cohen G, Jalles JT, Loungani P, Marto R (2018) The long-run decoupling of emissions and output: Evidence from the largest emitters. Energy Policy 118:58-68. https://doi.org/10.1016/j.enpol.2018.03.028

European Commission (2020a) European climate law - achieving climate neutrality by 2050. https://ec.europa.eu/info/law/better-regulation/have-your-say/initiatives/12108European-climate-law-achieving-climate-neutrality-by-2050
European
Commission
(2020b)
Eurostat
Database. https://ec.europa.eu/eurostat/data/database. 


\section{$\underline{05468-5}$}

726

727

728

729

730

731

732

733

734

735

736

737

738

739

740

741

742

743

744

745

746

747

748

749

750

751

752

753

754

755

756

Federal Ministry for Economic Affairs and Energy (BMWI) (2019) Industrial Policy, A modern industrial policy. https://www.bmwi.de/Redaktion/EN/Dossier/modern-industrypolicy.html

Federal Ministry for the Environment, Nature Conservation, Building and Nuclear Safety (BMUB) (2016) Public Relations Division. Climate Action Plan 2050, Principles and goals of the German government's climate policy.

Gonzalez PF, Landajo M, Presno MJ (2014) The driving forces behind changes in $\mathrm{CO}_{2}$ emission levels in EU-27. Differences between member states. Environ Sci Policy 38: 1116. https://doi.org/10.1016/j.envsci.2013.10.007

Haein K, Minsang K, Hyunggeun K, Sangkyu P (2020) Decomposition Analysis of $\mathrm{CO}_{2}$ Emission from Electricity Generation: Comparison of OECD Countries before and after the Financial Crisis. Energies 13(14):3522-3538. https://doi.org/10.3390/en13143522.

Hatzigeorgiou E, Polatidis $\mathrm{H}$, Haralambopoulos D (2008) $\mathrm{CO}_{2}$ emissions in Greece for 1990-2002: A decomposition analysis and comparison of results using the Arithmetic Mean Divisia Index and Logarithmic Mean Divisia Index techniques. Energy 33(3):492499. https://doi.org/10.1016/j.energy.2007.09.014

Hatzigeorgiou E, Polatidis $\mathrm{H}$, Haralambopoulos D (2010) Energy $\mathrm{CO}_{2}$ Emissions for 1990-2020: A Decomposition Analysis for EU-25 and Greece. Energy Sources A: Recovery Util Environ Eff https://doi.org/10.1080/15567030902937101

Herrendorf B, Rogerson R, Valentinyi A (2014) Growth and structural transformation. In: Aghion P. and Durlauf S.N., editors, Handbook of Economic Growth, Elsevier, Amsterdam.

Hu P, Zhou Y, Gao Y, Zhou J, Wang G, Zhu G (2021) Decomposition analysis of industrial pollutant emissions in cities of Jiangsu based on the LMDI method. Environ Sci Pollut Res. https://doi.org/10.1007/s11356-021-15741-1

Intergovernmental Panel on Climate Change (IPCC) (2006) IPCC guidelines for national greenhouse gas inventories. Intergovernmental panel on climate change. London.

International Energy Agency (IEA) (2020a) Data \& Statistics. https://www.iea.org/dataand-statistics

International Energy Agency (IEA) (2020b) Germany 2020 Energy Policy Review.

Jiang R, Li R, Wu Q (2019) Investigation for the Decomposition of Carbon Emissions in the USA with C-D Function and LMDI Methods. Sustainability 11(2):334-349. https://doi.org/10.3390/su11020334. 

Review of Sustainable Energy Policies for the Promotion of Renewable Energy Sources. Sustainability 12(12):5078. https://doi.org/10.3390/su12125078

763

764

765

766

767

768

769

770

771

772

773

774

775

776

777

778

779

780

781

782

783

784

785

786

787

788

789

790

791

792

793

794

Martínez DM, Ebenhack BW, Wagner TP (2019) Chapter 1 - Introductory concepts, Energy Efficiency, Elsevier. https://doi.org/10.1016/B978-0-12-812111-5.00001-9

Sadorsky P (2020) Energy Related $\mathrm{CO}_{2}$ Emissions before and after the Financial Crisis. Sustainability 12(9):3867-3889. https://doi.org/10.3390/su12093867

Shahiduzzaman Md, Layton A (2017) Decomposition analysis for assessing the United States 2025 emissions target: How big is the challenge? Renew Sustain Energy Rev 67: 372-383. https://doi.org/10.1016/j.rser.2016.08.042

Song Y, Zhang M, Zhou M (2019) Study on the decoupling relationship between $\mathrm{CO}_{2}$ emissions and economic development based on two-dimensional decoupling theory: A case between China and the United States. Ecol Indic 102(5):230-236. https://doi.org/10.1016/j.ecolind.2019.02.044

Tapio P (2005) Towards a theory of decoupling: degrees of decoupling in the EU and the case of road traffic in Finland between 1970 and 2001. Transp Policy 12(2):137-151. https://doi.org/10.1016/j.tranpol.2005.01.001

Telli A, Erat S, Demir B (2020) Comparison of energy transition of Turkey and Germany: energy policy, strengths/weaknesses and targets. Clean Technol Environ Policy 23(3):1-15. https://doi.org/10.1007/s10098-020-01950-8

The World Bank Group (2020) World Bank Open Data. https://data.worldbank.org

Tol RSJ, Pacala SW, Socolow RH (2009) Understanding Long-Term Energy Use and Carbon Dioxide Emissions in the USA. J Policy Model 31(3):425-445. https://doi.org/10.1016/j.jpolmod.2008.12.002

U.S Energy Information Administration (2020a) International Statistics \& Analysis. Use of Energy explained. https://www.eia.gov/energyexplained/use-of-energy/

U.S Energy Information Administration (2020b) U.S. Energy-Related Carbon Dioxide Emissions, 2019. https://www.eia.gov/environment/emissions/carbon/

van Neuss L (2019) The drivers of structural change. J Econ Surv 33(1):309-349. https://doi.org/10.1111/joes.12266

Vinuya F, DiFurio F, Sandoval E (2010) A decomposition analysis of $\mathrm{CO}_{2}$ emissions in the United States. Appl Econ Lett 17(10):925-931. https://doi.org/10.1080/00036840902762688

Wang C, Chen J, Zou J (2005) Decomposition of energy-related $\mathrm{CO}_{2}$ emission in China: 1957-2000. Energy 30(1):73-83. https://doi.org/10.1016/j.energy.2004.04.002 
Wang Q, Zhao M, Li R, Su M (2018) Decomposition and decoupling analysis of carbon emissions from economic growth: A comparative study of China and the United States. J Clean Prod 197:178-184. https://doi.org/10.1016/j.jclepro.2018.05.285

Wang Z, Jiang Q, Dong K, Mubarik MS, Dong X (2020) Decomposition of the US $\mathrm{CO}_{2}$ emissions and its mitigation potential: An aggregate and sectoral analysis. Energy Policy 147:111925. https://doi.org/10.1016/j.enpol.2020.111925

Ward JD, Sutton PC, Werner AD, Costanza R, Mohr SH, Simmons CT (2016) Is Decoupling GDP Growth from Environmental Impact Possible? PLoS One 11(10): e0164733. https://doi.org/10.1371/journal.pone.0164733

Watson MW (2014) Inflation Persistence, the NAIRU, and the Great Recession. Am Econ Rev 104(5):31-36. https://doi.org/10.1257/aer.104.5.31

Wu L, Kaneko S, Matsuoka S (2005) Driving forces behind the stagnancy of China's energy-related $\mathrm{CO}_{2}$ emissions from 1996 to 1999: the relative importance of structural change, intensity change and scale change. Energy Policy 33(3):319-335. https://doi.org/10.1016/j.enpol.2003.08.003

Yang P, Liang X, Drohan PJ. (2020) Using Kaya and LMDI models to analyze carbon emissions from the energy consumption in China. Environ. Sci Pollut Res 27:2649526501. https://doi.org/10.1007/s11356-020-09075-7

Yao C, Feng K, Hubacek K (2015) Driving forces of $\mathrm{CO}_{2}$ emissions in the $\mathrm{G} 20$ countries: An index decomposition analysis from 1971 to 2010. Ecol Inform 26(1):93-100. https://doi.org/10.1016/j.ecoinf.2014.02.003

Yasmeen H, Wang Y, Zameer H, Solangi YA (2020) Decomposing factors affecting CO2emissions in Pakistan: insights from LMDI decomposition approach. Environ Sci Pollut Res 27:3113-3123. https://doi.org/10.1007/s11356-019-07187-3

Zhang J, Fan Z, Chen Y, Gao J, Liu W (2020) Decomposition and decoupling analysis of carbon dioxide emissions from economic growth in the context of China and the ASEAN countries. Sci Total Environ 714:136649. https://doi.org/10.1016/j.scitotenv.2020.136649 


\section{Supplementary Files}

This is a list of supplementary files associated with this preprint. Click to download.

- SupplementaryInformationFile.docx 